\title{
Carbon balance of a three crop succession over two cropland sites in South West France
}

\author{
Béziat $\overline{\overline{\bar{P}}}$ ierre, Ceschia Eric*, Dedieu Gérard \\ Centre d'Etudes Spatiales de la BIOsphère (CESBIO), 18 Avenue Edouard Belin bpi 2801, 31401 Toulouse Cedex 9, France
}

\section{A R T I C L E I N F O}

\section{Article history:}

Received 17 October 2008

Received in revised form 6 May 2009

Accepted 7 May 2009

\section{Keywords:}

Crop

Carbon balance

Net ecosystem exchange

Eddy covariance

Management

Uncertainties

\section{A B S T R A C T}

Long term flux measurements of different crop species are necessary to improve our understanding of management and climate effects on carbon flux variability as well as cropland potential in terrestrial carbon sequestration. The main objectives of this study were to analyse the seasonal dynamics of $\mathrm{CO}_{2}$ fluxes and to establish the effects of climate and cropland management on the annual carbon balance.

$\mathrm{CO}_{2}$ fluxes were measured by means of the eddy correlation (EC) method over two cropland sites, Auradé and Lamasquère, in South West France for a succession of three crops: rapeseed, winter wheat and sunflower at Auradé, and triticale, maize and winter wheat at Lamasquère. The net ecosyst exchange (NEE) was partitioned into gross ecosystem production (GEP) and ecosystem respiration $\left(R_{\mathrm{E}}\right)$ and was integrated over the year to compute net ecosystem production (NEP). Different methodologies tested for NEP computation are discussed and a methodology for estimating NEP uncertainty is presented.

NEP values ranged between $-369 \pm 33 \mathrm{~g} \mathrm{C} \mathrm{m}^{-2} \mathrm{y}^{-1}$ for winter wheat at Lamasquère in 2007 and $28 \pm 18 \mathrm{~g} \mathrm{C} \mathrm{m}^{-2} \mathrm{y}^{-1}$ for sunflower at Auradé in 2007. These values were in good agreement with NEP values reported in the literature, except for maize which exhibited a low development compared to the literature. NEP was strongly influenced by the length of the net carbon assimilation period and by interannual climate variability. The warm 2007 winter stimulated early growth of winter wheat, causing large differences in GEP, $R_{\mathrm{E}}$ and NEE dynamics for winter wheat when compared to 2006. Management had a strong impact on $\mathrm{CO}_{2}$ flux dynamics and on NEP. Ploughing interrupted net assimilation during voluntary re-growth periods, but it had a negligible short term effect when it occurred on bare soil. Re-growth events after harvest appeared to limit carbon loss: at Lamasquère in 2005 re-growth contributed to store up to $50 \mathrm{~g} \mathrm{C} \mathrm{m}^{-2}$. Differences in NEE response to climatic variables (VPD, light quality) and vegetation index were addressed and discussed.

Net biome production (NBP) was calculated yearly based on NEP and considering carbon input through organic fertilizer and carbon output through harvest. For the three crops, the mean NBP at Auradé indicated a nearly carbon balanced ecosystem, whereas Lamasquère lost about $100 \mathrm{~g} \mathrm{C} \mathrm{m}^{-2} \mathrm{y}^{-1}$; therefore, the ecosystem behaved as a carbon source despite the fact that carbon was imported through organic fertilizer. Carbon exportation through harvest was the main cause of this difference between the two sites, and it was explained by the farm production type. Lamasquère is a cattle breeding farm, exporting most of the aboveground biomass for cattle bedding and feeding, whereas Auradé is a cereal production farm, exporting only seeds.

(c) 2009 Published by Elsevier B.V.

\section{Introduction}

Understanding and quantifying carbon sources and sinks is a major challenge for the scientific community. The main goal is to assess the carbon balance, to see what practices result in lower emissions and to recommend their use. In terrestrial ecosystems, the massive conversion of forest to cropland has caused an important loss of soil carbon, mainly through soil respiration

\footnotetext{
* Corresponding author. Tel.: +33 5615585 27; fax: +33 561558500 .

E-mail address: eric.ceschia@cesbio.cnes.fr (C. Eric).
}

(Robert and Saugier, 2003). Currently, croplands represent about one third of Europe's land surface (Smith et al., 2005). Over the last 8000 years, agriculture has had a significant impact on the atmospheric concentration of $\mathrm{CO}_{2}$ and $\mathrm{CH}_{4}$ (Salinger, 2007). Impacts of agriculture on global climate changes through greenhouse gas emissions and changes in the physical properties of land $\operatorname{cov} \bar{\equiv}$ ve been summarized in the recent analyses of Desjardins and Sivakumar (2007) and Raddatz (2007). Hutchinson et al. Q122 (2007) concluded that the carbon sequestration potential of 23 croplands should be considered as a modest but non-negligible 24 contribution to climate change mitigation (between $3 \%$ and $6 \%$ of 25 fossil fuel contribution to climate changes), but quantification of 26

0168-1923/\$ - see front matter (c) 2009 Published by Elsevier B.V

doi:10.1016/j.agrformet.2009.05.004 
crop carbon sequestration potential remains very uncertain. Therefore, variability in stocks and fluxes of carbon in croplands is a theme of major interest. However, most studies involving micrometeorological measurements by the eddy correlation (EC) method have focused on forest ecosystems, some have investigated grasslands and only a minority has concentrated on croplands.

Recent studies on croplands have focused on seasonal patterns of $\mathrm{CO}_{2}$ flux and annual carbon balance for different crops. The most studied croplands were maize-soybean rotations in North America (Baker and Griffis, 2005; Bernacchi et al., 2005; Hollinger et al., 2005; Pattey et al., 2002; Suyker et al., 2005, 2004; Verma et al., 2005). However, rice (Saito et al., 2005), sugar beat (Moureaux et al., 2006), winter wheat and triticale (Ammann et al., 1996; Anthoni et al., 2004a; Baldocchi, 1994) have also been studied. In Soegaard et al. (2003), an attempt was made to scale up crop fluxes by comparing EC measurements placed on a tall mast coupled with a footprint analysis of EC measurements over five different crop plots (winter wheat, spring and fall barley, maize and grass) around the tall mast.

Some of recent studies on croplands reveal the importance of management practices on plot carbon balance. In Baker and Griffis (2005), $\mathrm{CO}_{2}$ flux measurements were carried out on two plots with similar climatic and soil conditions but different management practices. The authors concluded that carbon gain caused by reduced tillage and intercropping compared to conventional management was compensated for by a drop in productivity and an increase in crop residue decomposition. However, it has been shown that the conversion of conventional tillage to no-till agriculture in maize/soybean crops in the USA might result in an annual net carbon sequestration of $20.77 \mathrm{Tg} C$ (Bernacchi et al., 2005, 2006). Hollinger et al. (2005) showed that considering biomass export and fuel combustion may transform a soybean crop from a sink to a source of carbon. Therefore, considering management to address whether a crop is a source or a sink is essential. Still, too few long-term accurate flux measurements over different crop species have been conducted to quantify management and climate effects on spatial and temporal flux variability, as well as to determine the potential role of cropland in terrestrial carbon sequestration.

In the present study, $\mathrm{CO}_{2}$ flux measurements were performed, using the EC method, during three cropping seasons in South West France at two crop sites with similar climates but different soils and management practices. The main objectives were (1) to adapt conventional EC data post-treatments, developed mainly for forest, to account for fast and discontinuous canopy structure variations specific to croplands, to evaluate the impact of these modified computational methods on annual net ecosystem carbon exchange (NEP) and estimate NEP uncertainty; (2) to analyse the seasonal dynamics and $\mathrm{CO}_{2}$ flux evolution of different crop species (rapeseed, triticale, winter wheat, maize and sunflower) in relation to management and climate; (3) to compare crop carbon assimilation efficiencies through analysis of light response curves; and (4) to establish the annual carbon balance for the different crops and evaluate the influence of management and climate.

\section{Materials and methods}

\subsection{Site descriptions}

Since 18 March 2005, micrometeorological and meteorological measurements have been performed over two cultivated plots, Auradé and Lamasquère, separated by $12 \mathrm{~km}$ and located near Toulouse (South West France). Both sites are part of the CarboEurope-IP Regional experiment (Dolman et al., 2006) and the CarboEurope-IP Ecosystem component (WP1) experiment.
Both sites have been cultivated for more than 30 years and experience similar climatic conditions but have different management practices, soil properties and topography. Crop rotations on both sites are quite representatives of the main regional crop rotations. Table 1 summarizes the main characteristics and general climate of the two sites.

The Auradé plot belongs to a private farmer and is located on a hillside area near the Garonne river terraces. The plot is characterised by a rapeseed/winter wheat/sunflower/winter wheat rotation. It was cultivated with rapeseed (Brassica napus L.) from 13-Sept-2004 (day-month-year) to 27-Jun-2005, with winter wheat (Triticum aestivum L.) from 27-Oct-2005 to 29-Jun2006 and with sunflower (Helianthus annuus L.) from 11-Apr-2007 to 20-Sept-2007. It was supplied with mineral fertilizer (204 and $124 \mathrm{~kg} \mathrm{~N} \mathrm{ha}^{-1}$ for rapeseed and winter wheat, respectively, and no fertilization for sunflower) and has never been irrigated. Superficial tillages (5-10 cm depth) were done after rapeseed harvest (04-Jul-2005 and 04-Aug-2005) to plough residues, and re-growth of crops and weeds into the soil. Deep tillages (30 cm depth) were performed before winter wheat sowing (22 and 23-Sept-2005) and before sunflower sowing (plough on 29 and 30-Sept-2006 and harrow on 12-Mar-2007).

The Lamasquère plot was cultivated with triticale (Triticosecale) from 24-Nov-2004 to 11-Jul-2005, with maize (Zea mays L.) used for silaging from 01-May-2006 to 31-Aug-2006 and with winter wheat (Triticum aestivum L.) from 18-Oct-2006 to 15-Jul-2007. This plot is part of an experimental farm owned by the Ecole Supérieure d'Agronomie de Purpan (ESAP). The instrumented site borders the "Touch" river and is characterised by a triticale/maize/winter wheat/maize rotation. Organic fertilisers $(150,115$ and $150 \mathrm{~kg} \mathrm{~N}$ $\mathrm{ha}^{-1}$ for triticale, maize and winter wheat, respectively) and mineral fertilisers $\left(89,91\right.$ and $234 \mathrm{~kg} \mathrm{~N} \mathrm{ha}^{-1}$ for triticale, maize and winter wheat, respectively) were supplied to the plot. To plough residues and manure into the soil, the plot was tilled superficially before the sowing of triticale (28-Sept-2004), and a non-inverting tillage was performed between the maize harvest and winter wheat sowing (10 and 11-Oct-2006). A deep tillage was done before maize sowing (plough on 01-Dec-2005 and harrow on 29 and 30-Mar-2006). The plot was irrigated when maize was cultivated, with a total amount of $147.8 \mathrm{~mm}$. In autumn 2004, triticale seeds were spread instead of being sown in a row, because the soil was too wet to allow the use of conventional tools.

\subsection{Field measurements}

\subsubsection{Flux measurements}

Masts were installed in the middle of each plot in order to optimize fetch in main wind directions (see Table 1). Secured enclosures surrounded the masts to avoid damage caused by wild animals. Management within the enclosures closely resembled the management in the rest of the fields. Turbulent fluxes of $\mathrm{CO}_{2}\left(F_{\mathrm{ct}}\right)$, water vapour (evapotranspiration, $E$ and latent heat, LE), sensible heat $(H)$ and momentum $(\tau)$ have been measured continuously by the EC method (Aubinet et al., 2000; Baldocchi, 2003; Grelle and Lindroth, 1996; Moncrieff et al., 1997) since 18-Mar-2005. The EC devices were mounted at heights of 2.8 and $3.65 \mathrm{~m}$ at Auradé and Lamasquère, respectively. Instrument heights were chosen to be at worst $1 \mathrm{~m}$ higher than crops at their maximum development. The EC system is made of a three-dimensional sonic anemometer (CSAT 3, Campbell Scientific Inc, Logan, UT, USA) and an open-path infrared gas analyzer (LI7500, LiCor, Lincoln, NE, USA). Data were recorded at $20 \mathrm{~Hz}$ on a data logger (CR5000, Campbell Scientific Inc, Logan, UT, USA) and stored on a 1 GB compact flash card. Zero and span calibrations were performed for $\mathrm{CO}_{2}$ and $\mathrm{H}_{2} \mathrm{O}$ every six month. 
Table 1

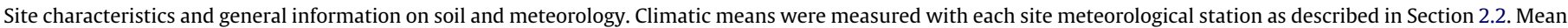

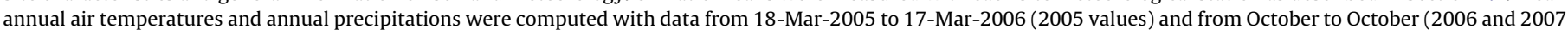

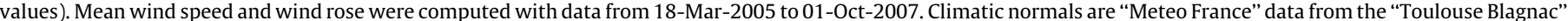
station (visible at http://www.infoclimat.fr/climatologie/index.php); they correspond to means calculated over 30 years (1961-1990).

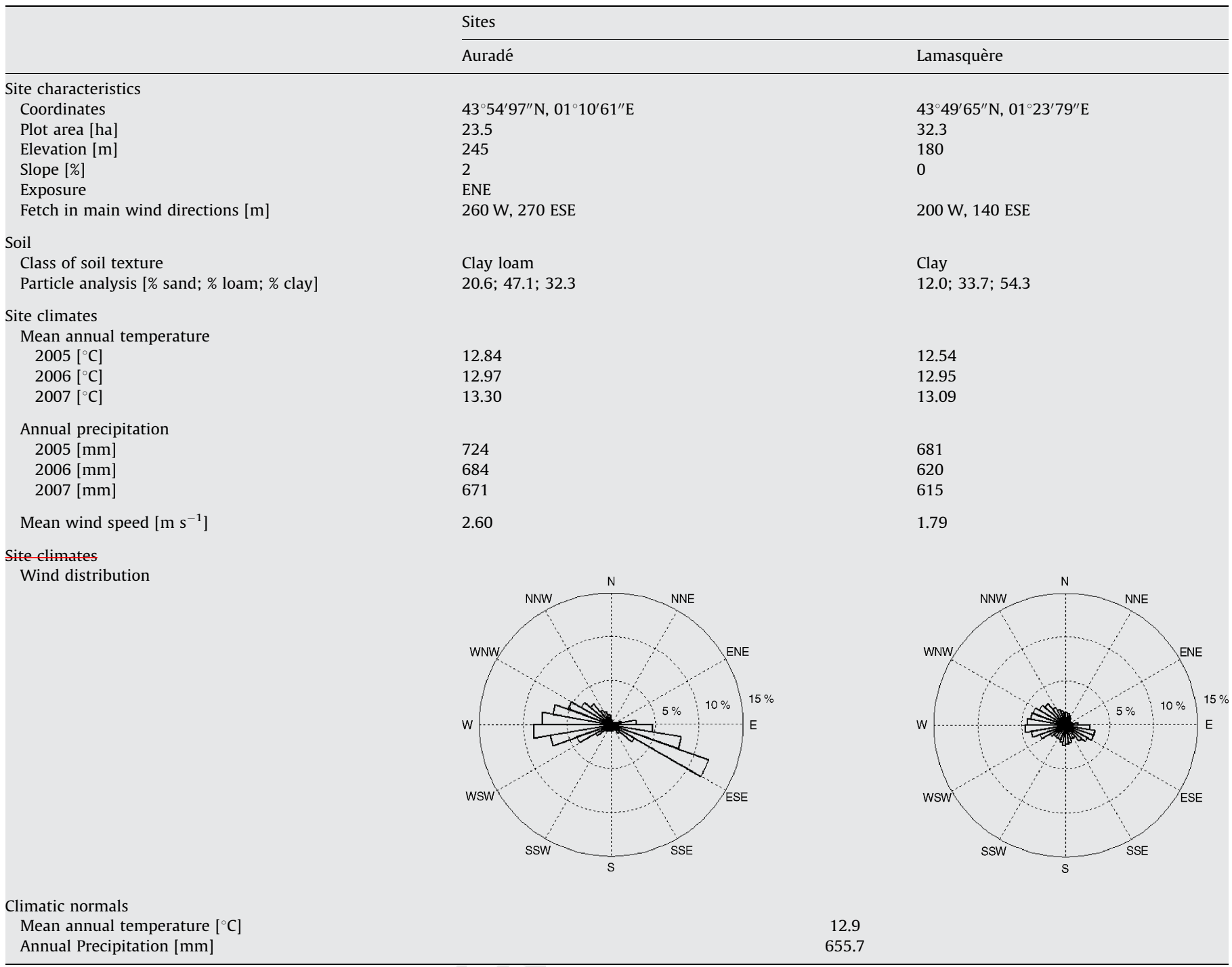

\subsubsection{Meteorological measurements}

Standard meteorological variables were recorded on each site to analyse and calculate turbulent fluxes. Different radiation components were measured: incoming and outgoing short-wave and long-wave radiation with a CNR1 (Kipp \& Zonen, Delft, NL); net radiation with a NR-lite (Kipp \& Zonen, Delft, NL); incoming photosynthetic photon flux density (PPFD) with a PAR-lite (Kipp \& Zonen, Delft, NL) and direct and diffuse PPFD with a BF2 (Delta-T, Cambridge, UK). Direct and diffuse PPFD measurements began in March 2005 at Lamasquère and in September 2005 at Auradé. Three PAR-LE sensors (PAR-LE, Solems, Palaiseau, France) were used to measure transmitted PPFD to soil and one to measure reflected PPFD above vegetation. Photosynthetic photon flux density absorbed by vegetation (aPPFD) was calculated as follows (Ruimy et al., 1995):

$\mathrm{aPPFD}=($ PPFD + rstPPFD $)-($ tPPFD + rtPPFD $)$

where rs is the soil reflectance for PPFD, tPPFD is the PPFD transmitted to soil and rtPPFD is the total reflected PPFD by both soil and vegetation measured above vegetation. The first and second term of the right-hand side of Eq. (1) correspond to incoming and outgoing PPFD relative to the vegetation, respectively. rs was estimated as the slope of the linear regression between rtPPFD and PPFD during bare soil periods between tillage and sowing. rs estimates were $0.145\left(R^{2}=0.81\right)$ at Lamasquère and $0.231\left(R^{2}=0.82\right)$ at Auradé. aPPFD was only calculated for periods with plant area index (PAI) higher than $1 \mathrm{~m}^{2} \mathrm{~m}^{-2}$ to limit spatial variability errors in tPPFD measurements caused by spatial heterogeneity in radiation at the floor and the limited number of sensors. During those periods, statistical differences between the PAR-LE sensors were low (relative standard deviation $<0.3$ ).

Air temperature and relative humidity were measured with a Vaisala probe (HMP35A, Vaisala, Helsinki, Finland). Precipitation was recorded with a ARG100 rain-gauge (Environmental Measurements Ltd., Sunderland, UK), atmospheric pressure with a BS4 sensor (BS4, Delta-T, Cambridge, UK), wind speed and direction with a 014A wind speed sensor and a 024A wind direction sensor (Met one instruments, inc., Grants Pass, OR, USA), respectively, at Lamasquère and a Young wind monitor (05103, Young, Traverse city, MI, USA) at Auradé. Surface radiative temperature was measured with a precision infrared temperature sensor (IRTS-P, 
Campbell Scientific Inc, Logan, UT, USA). Soil temperature, moisture and heat flux profiles were measured with TP107 (Campbell Scientific Inc, Logan, UT, USA), CS616 (Campbell Scientific Inc, Logan, UT, USA) and HFP01 (Hukseflux, Delft, NL) probes, respectively. Three measurement repetitions were performed on each site at depths of 0.05, 0.10, $0.30 \mathrm{~m}$ and a single measurement was taken at depths of 0.60 and $1 \mathrm{~m}$ at Auradé and Lamasquère, respectively. Since 03-Nov-2006 at Auradé and 24Aug-2006 at Lamasquère, $\mathrm{CO}_{2}$ atmospheric concentration, air temperature and relative humidity profiles $(50$ and $150 \mathrm{~cm}$ aboveground) have been measured using GMP343 (GMP343, Vaisala, Helsinki, Finland) and HMP50 (HMP50, Vaisala, Helsinki, Finland), respectively. These measurements were then used for multi-layer $\mathrm{CO}_{2}$ storage calculations (see Section 2.3).

\subsubsection{Biomass inventories and photosynthetic surface measurements}

Destructive measurements were operated to analyse biomass and PAI dynamics. In 2005, randomly spatially distributed plants were collected monthly in each field. Between each destructive measurement date, 30 and 20 randomly spatially distributed hemispherical photographs were taken at Auradé and Lamasquère, respectively, to analyse PAI temporal evolution more accurately (Demarez et al., in press). This method was cross-calibrated with destructive measurements. In 2006 and in 2007, plants were collected on the two diagonals of the fields, monthly during slow vegetation development periods and every two weeks during fast vegetation development periods. The aboveground dry mass (DM) distribution among organs was measured using OHAUS balance (SPU 4001, OHAUS, Pine Brook, NJ, USA). PAI was defined as the half surface of all green organs and leaf area index (LAI) as the half surface of green leaves; it was measured by means of a LiCor planimeter (LI3100, LiCor, Lincoln, NE, USA). For rapeseed, maize and sunflower, 30 plants were collected at each date. However, because of the large rapeseed plant sizes, only 10 plants were sampled at Auradé from April 2005 until harvest. This reduced sampling and the large variability observed in the field may explain the large PAI standard deviation observed on 28-Apr-2005 (Fig. 2(a)). For winter wheat, ten $1.5 \mathrm{~m}$ long rows were collected at each sampling date. Because seeds were not sown in rows, triticale was sampled by collecting ten $0.25 \mathrm{~m}^{2}$ plots.

After harvest, crop residues were sampled on ten $0.25 \mathrm{~m}^{2}$ plots for each crop. Analyses of plant and residue carbon content were performed just before harvest. Exported carbon from the plot during harvest (Exp) was calculated by subtracting the carbon content in the aboveground biomass (AGB) and the carbon content in crop residues (Residues). Exp standard deviation, $\sigma(\operatorname{Exp})$, was calculated from $\sigma$ (AGB) and $\sigma$ (Residues) as:

$\sigma(\operatorname{Exp})=\sqrt{\frac{\sigma(\mathrm{AGB})^{2}}{\mathrm{nb}}+\frac{\sigma(\text { Residues })^{2}}{\mathrm{nr}}}$

where $\mathrm{nb}$ is the number of aboveground biomass samples, and $\mathrm{nr}$ the number of residues samples. For this calculation, we assume a normal distribution and independence between AGB and Residues. We choose to calculate Exp from our destructive samples instead of using the yield data from the farmers, because their yield estimates correspond to mean yield values for several plots grown with the same crop on the farm. However, both Exp and yields were in good agreement (slope $=0.97$, intercept $=19 \mathrm{~g} \mathrm{C} \mathrm{m}^{-2}, R^{2}=0.98$ ).

\subsection{Flux data treatments}

\subsubsection{Flux calculation}

Atmospheric convention was used in this paper with negative flux moving downward from the atmosphere to the ecosystem and positive flux moving upward. EdiRe software (Robert Clement, ()
1999, University of Edinburgh, UK) was used to calculate fluxes on 5 and 30 min intervals following CarboEurope-IP recommendations. A 2D rotation was applied in order to align the streamwise wind velocity component with the direction of the mean velocity vector. Fluxes were corrected for spectral frequency loss (Moore, $1986) . F_{\mathrm{ct}}, E$ and LE fluxes were corrected for air density variations (Webb et al., 1980).

Before temperature, relative humidity and $\mathrm{CO}_{2}$ concentration profiles below the $\mathrm{EC}$ system were measured, changes in $\mathrm{CO}_{2}$ storage $\left(F_{\mathrm{cs}}\right)$ were calculated as described in Aubinet et al. (2001) but with only one measuring height for $\mathrm{CO}_{2}$ concentration:

$F_{\mathrm{cs}}=\frac{P_{\mathrm{a}}}{R T_{\mathrm{a}}} \cdot \frac{\partial c}{\partial t} \cdot h_{\mathrm{ec}}$

where $h_{\mathrm{ec}}$ is the EC system height, $P_{\mathrm{a}}$ is the atmospheric pressure at $h_{\mathrm{ec}}, T_{\mathrm{a}}$ is the air temperature at $h_{\mathrm{ec}}, R$ is the molar gas constant, and $c$ is the $\mathrm{CO}_{2}$ concentration at $h_{\mathrm{ec}}$. This methodology is known to underestimate $F_{\mathrm{cs}}$ by about 20-25\% (Saito et al., 2005). However, it is often used for ecosystems with short vegetation, such as croplands and grasslands, where $F_{\mathrm{cs}}$ is assumed to be low (Anthoni et al., 2004a; Moureaux et al., 2006; Suyker et al., 2005; Verma et al., 2005; Wohlfahrt et al., 2005; Xu and Baldocchi, 2004). Net ecosystem exchange (NEE) was then calculated as the sum of $F_{\mathrm{ct}}$ and $F_{\text {cs. }}$. When $\mathrm{CO}_{2}$ concentration profiles below the EC were measured, Eq. (3) was used to calculate storage in each $h_{1}$ high layer of the profile. $F_{\mathrm{cs}}$ below the EC system was then calculated as the sum of storage in each $h_{1}$ high layer.

\subsubsection{Flux filtering and quality control}

Fluxes were filtered to remove data corresponding to technical problems, inappropriate meteorological conditions for EC measurements, low spatial representativeness, and violation of EC theory (Aubinet et al., 2000; Baldocchi, 2003; Foken and Wichura, 1996).

Initially, flux data were discarded if the scalar means, scalar standard deviations or flux values were out of realistic bounds.

$F_{\mathrm{ct}}, E$ and $\mathrm{LE}$ were also discarded during rainfall periods and the half-hour following rainfall events because of a dysfunction of the open-path gas analyzer and sonic anemometer in wet conditions. However, Ruppert et al. (2006) showed that rain gauge measurements are not sufficiently accurate to identify light precipitation events; therefore, outliers remain. In the present study, these remaining outliers, as well as those caused by the wet gas analyzer or other events, were detected by the comparison of half-hourly fluxes $X_{i}$ with a 200 data point moving mean $\left(X_{g i}\right)$ and standard deviation $\left(X_{s d i}\right)$ as follows:

if $X_{i}<X_{g i}-\left(2.5 \cdot X_{s d i}\right)$

Or

if $X_{i}>X_{g i}+\left(2.5 \cdot X_{s d i}\right)$

then $X_{i}$ was discarded from the dataset. This procedure was performed separately for day-time and night-time data. Nighttime was defined as $P P F D<5 \mu \mathrm{mol} \mathrm{m} \mathrm{m}^{-2} \mathrm{~s}^{-1}$ and solar elevation angles $<0^{\circ}$.

A friction velocity $(u *)$ criteria was used to determine periods within the low turbulence regime when fluxes are systematically underestimated by EC measurements (Aubinet et al., 2000; Falge et al., 2001; Gu et al., 2005; Papale et al., 2006; Reichstein et al., 2005). Reichstein et al. (2005) proposed an automatic method to determine the $u *$ threshold applied every three months to take into account changes in phenology and canopy properties. However, in croplands, changes in canopy structure are fast and discontinuous because of harvest and tillage. Therefore, we defined crop functioning periods (CFP) between dates of sowing, maximum crop development, harvest and tillage. A $u *$ threshold was then 
determined with the Reichstein et al. (2005) automatic method for each CFP. Flux data below the highest $u *$ threshold were discarded from the dataset to maintain the same conservative approach as Reichstein et al. (2005).

For each half-hourly flux value, a fetch including $90 \%$ of the flux $\left(D_{90 \_} i\right)$ was computed with the Kljun et al. (2004) parameterisation. This fetch was compared with the distance between the mast and the edge of the plot in the main wind direction for the corresponding half-hour $\left(D_{i}\right)$. If $D_{90 \_i}>D_{i}$, fluxes were discarded because we assumed that it was not sufficiently representative of the plot.

Stationarity and development of turbulent conditions are important hypotheses for EC measurements. They were tested with the steady state test and the integral turbulence characteristic test recommended by Foken and Wichura (1996) and revisited by Foken et al. (2004). Flux data were flagged 0,1 or 2 with 0 corresponding to the best quality and 2 to the worst (see Foken et al. (2004) for details). However, the steady state test was applied only if an absolute threshold between covariance over $30 \mathrm{~min}$ and means of covariances over 5 min for the corresponding half-hour was reached. This method allows us to keep fluxes corresponding to covariances close to zero that failed the steady state test for mathematical reasons. The absolute threshold was defined as the EC measurement estimated accuracy; it was fixed, based on our expertise, at $1.25 \mu \mathrm{mol} \mathrm{CO}_{2} \mathrm{~m}^{-2} \mathrm{~s}^{-1}$ for NEE and $10 \mathrm{~W} \mathrm{~m}^{-2}$ for energy fluxes $H$ and LE. Fluxes corresponding to an unrotated vertical wind velocity mean $w>0.35 \mathrm{~m} \mathrm{~s}^{-1}$ were also flagged 2 , because measurements over this threshold cannot be properly corrected with rotation procedures (Foken and Wichura, 1996; Göckede et al., 2004). In the remainder of the study, filtered NEE correspond to values that pass all the filters described above and with a quality flag lower than 2 .

\subsubsection{Flux gapfilling and NEE partitioning between GEP and $R_{E}$}

To compute daily to annual sums of fluxes, NEE gaps were filled in all the dataset. The algorithm described in Reichstein et al. (2005) was used for gapfilling; it was not applied to the whole dataset but on each CFP independently to account for the fast and discontinuous changes in canopy properties. After gapfilling was achieved, NEE was partitioned into gross ecosystem production (GEP) and ecosystem respiration $\left(R_{\mathrm{E}}\right)$ components. The method described in Reichstein et al. (2005), based on the Lloyd and Taylor (1994) model parameters optimisation, was followed:

$R_{\mathrm{E}}=R_{\text {ref }} \cdot \exp \left(E_{0}\left(\frac{1}{T_{\text {ref }}-T_{0}}-\frac{1}{T_{\mathrm{a}}-T_{0}}\right)\right)$

where $R_{\text {ref }}$ is the respiration at the reference temperature $T_{\text {ref }}$ (here $10{ }^{\circ} \mathrm{C}$ therefore $R_{\mathrm{ref}}=R_{10}$ ), $E_{0}$ is a parameter describing $R_{\mathrm{E}}$ sensitivity to temperature, and $T_{0}$ is a temperature scale parameter kept constant at $-46.02{ }^{\circ} \mathrm{C}$ as in Lloyd and Taylor (1994) to avoid any over-parameterization of the model as explained by Reichstein et al. (2005). First, the model parameter $E_{0}$ was optimised using nocturnal filtered NEE (equal to the observed ecosystem respiration) for each CFP, because it is strongly correlated to canopy properties (see Reichstein et al. (2005) for a full description of the optimisation process). Then $R_{10}$ was optimised with nocturnal filtered NEE for five days sliding windows with a two day step and interpolated every half-hour. Diurnal $R_{\mathrm{E}}$ was then calculated using Equation 5 with optimised $E_{0}$ and $R_{10}$ and diurnal $T_{\mathrm{a}}$. Diurnal GEP was finally calculated as the difference between the diurnal gapfilled NEE and the diurnal calculated $R_{\mathrm{E}}$.

\subsubsection{Carbon balance calculation and uncertainty assessments}

Net ecosystem production (NEP) was defined as the annual integration of half-hourly NEE values. NEP was computed from early October to late September, because this period generally begins after summer crop harvest and before the beginning of winter crop sowing. Therefore, this integration period is valid for both winter and summer crop species. However, in 2005, because continuous EC measurements started on 18-Mar-2005, the NEP for rapeseed at Auradé and triticale at Lamasquère were computed between 18-Mar-2005 and 17-Mar-2006. Although this integration period is not ideal because growth had already started in March, these data were integrated into the analysis because of the lack of flux data concerning triticale and rapeseed in the literature.

Three different sources of random errors were investigated to asses NEP uncertainty:

(1) The uncertainty introduced in NEP by the random error of the systematic $u *$ threshold determination $\sigma(\mathrm{NEPu})$ was assessed with the same bootstrapping approach as in Papale et al. (2006). Data were re-sampled 100 times using the bootstrap approach to determine $100 u *$ thresholds. NEE were then filtered with the new $u *$ thresholds (NEEu) and gapfilled. All other treatments on NEEu were the same as those described in Section 2.3.2. NEP from the $100 u *$ thresholds (NEPu) were then computed. $\sigma(\mathrm{NEPu})$ was calculated as the standard deviation of all the NEPu.

(2) Random errors in measurement can also introduce uncertainties in NEP via gapfilling and data integration (Dragoni et al., 2007; Rannik et al., 2006; Richardson and Hollinger, in press). We followed the Richardson and Hollinger (in press) methodology to calculate the uncertainty introduced in NEP by the random errors in measurement $(\sigma(\mathrm{NEPr}))$ in the following steps:

- Random errors $(\delta)$ were calculated as the differences between fluxes in similar climatic conditions on two successive days (Richardson et al., 2006).

A relation between $\sigma(\delta)$ and NEE was established for 20 NEE bins with the same number of data in each bin. Both sites were included in this relation, because they have the same instrumentation set up and the same ecosystem type. The following relations were found:

$$
\begin{aligned}
& \sigma(\delta)=-0.152 \mathrm{NEE}+0.87 \text { for } \mathrm{NEE}={ }_{\Lambda} 0\left(R^{2}=0.82\right) \\
& \sigma(\delta)=-0.204 \mathrm{NEE}+0.47 \text { for } \mathrm{NEE}={ }_{\mathrm{\Lambda}} 0\left(R^{2}=0.63\right)
\end{aligned}
$$

- Random noise from a double exponential distribution with 0 mean and $\sigma(\delta)$ standard deviation calculated from Equation $6 \mathrm{a}$ and $6 \mathrm{~b}$ was added to filtered NEE (NEEr). NEEr was then gapfilled, and the noisy NEP (NEPr) was computed. This last step was repeated 100 times, and $\sigma(\mathrm{NEPr})$ was calculated as the standard deviation of all NEPr.

(3) The uncertainty introduced in NEP by the gapfilling method errors $\sigma$ (NEPgap) was analysed through a gap distribution impact analysis. First, filtered NEE were gapfilled. Then random noise from a double exponential distribution with 0 mean and $\sigma(\delta)$ standard deviation (Eqs (6a) and (6b)) was added to the modelled NEE resulting from gapfilling procedures; no random noise was added to the filtered NEE. This procedure was done to avoid the smoothing impact of gapfilling procedures. Then gaps (same number, same size, and with approximately the same distribution between night and day as observed in filtered NEE) were randomly introduced in this gapfilled NEE (NEEgap). NEEgap was then gapfilled and integrated to compute NEP (NEPgap). Gap re-introduction and NEPgap computation was done 100 times. $\sigma$ (NEPgap) was calculated as the standard deviation of all the NEPgap.

Assuming a normal distribution of NEPu, NEPr and NEPgap and that these three sources of error were independent, NEP standard deviation, $\sigma(\mathrm{NEP})$, was estimated as the quadratic sum of $\sigma(\mathrm{NEPu})$, $\sigma$ (NEPr) and $\sigma$ (NEPgap). NEP uncertainty was reported at a $95 \%$ 
confidence interval as $2 \sigma(\mathrm{NEP})$. Although this method is not an exhaustive description of random and systematic error associated with the EC method (for more details see Anthoni et al., 2004a; Goulden et al., 1996; Moncrieff et al., 1996), it allows estimation of NEP uncertainty in a systematic way, valid for all ecosystem type, and with the main sources of error caused by standard flux data treatments.

Carbon output through Exp and input through organic fertilization (OF) were analysed to evaluate management effects on carbon balance at the plot scale. Therefore, net biome production (NBP) was defined as:

$\mathrm{NBP}=\mathrm{NEP}+\mathrm{OF}+\mathrm{Exp}$

As in Hollinger et al. (2005), Exp was considered a rapid carbon release to the atmosphere; thus, it was positive. OF was considered a carbon input to the plot, and thus was negative. The standard deviation of $\mathrm{OF}, \sigma(\mathrm{OF})$, was calculated from analyses of the carbon content in organic fertiliser provided by the farmer. Assuming independence and normality of the different error sources, $\sigma(\mathrm{NBP})$ was calculated as the quadratic sum of $\sigma(\mathrm{NEP}), \sigma(\operatorname{Exp})$ and $\sigma(\mathrm{OF})$.

\subsubsection{Net ecosystem exchange (NEE) response to light}

Only filtered NEE data were used for the light response analysis to avoid artificial relations between PPFD and gapfilled NEE. Relations between daytime NEE $\left(\mathrm{NEE}_{\mathrm{d}}\right)$ and aPPFD were $\operatorname{det}$ mined at each crop maximum development (PAz$\max -0.5 \leq \mathrm{PAI} \leq \mathrm{PAI}_{\max }$ where $\mathrm{PAI}_{\max }$ is the maximal value of $\mathrm{PAI}$ ) to limit crop dynamics effects on these relations. A nonrectangular hyperbolic light response model (Gilmanov et al., 2003) was fitted to each dataset:

$$
\begin{aligned}
\mathrm{NEE}_{\mathrm{d}}= & \frac{1}{2 \theta}(\alpha-\mathrm{aPPFD}+\beta \\
& \left.-\sqrt{(\alpha-\mathrm{aPPFD}+\beta)^{2}-4 \alpha \beta \theta \cdot \mathrm{aPPFD}}\right)_{-\bar{\alpha} \mathcal{}}
\end{aligned}
$$

where $\alpha$ is the initial slope of the light response curve, $\beta$ is $\mathrm{NEE}_{\mathrm{d}}$ at light saturation, $\gamma$ is the respiration term and $\theta$ is the curvature parameter $(0<\theta \leq 1)$. All fitted parameters and fitting statistics are reported in Table 3. Periods with high vapour pressure deficit (VPD), leading to a decrease in stomatal conductance and therefore to a decrease in $\mathrm{NEE}_{\mathrm{d}}$, were discarded from this analysis because this phenomenon was not accounted for in Eq. (8). VPD thresholds were estimated for each crop by the analysis of the distribution of NEE residuals $\left(\mathrm{NEE}_{\mathrm{res}}\right)$, computed as the difference between observed NEE and modelled NEE by Eq. (8). NEE res were averaged for $1 \mathrm{hPa}$ VPD bins. VPD threshold was defined as the lower VPD bin with $\mathrm{NEE}_{\text {res }}$ averages significantly higher than 0 (one-sample unpaired $t$-test, $p$-value $<0.05$ ), meaning a systematic overestimation of $\mathrm{NEE}_{\mathrm{d}}$ by the model beyond this threshold.

$\mathrm{NEE}_{\text {res }}$ were also analysed against aPPFD, soil water content (SWC) and $T_{\mathrm{a}}$ (data not shown). For aPPFD and SWC, NEE $\mathrm{E}_{\text {res }}$ were randomly distributed around 0 with no clear pattern. These results indicate a satisfying $\mathrm{NEE}_{\mathrm{d}}$ representation by Eq. (8) and show that no evident water stress was observed for any crop at maximum development. At high $T_{\mathrm{a}}$, modelled $\mathrm{NEE}_{\mathrm{d}}$ overestimations were observed; however, a strong correlation between VPD and $T_{\mathrm{a}}$ $\left(R^{2}=0.78\right.$ on average for the 6 datasets) leads us to think that this observation is mostly due to VPD.

\section{Results and discussion}

\subsection{Site meteorology}

Annual climatic means from our two stations were compared to climatic normals (30 year average) recorded at the "Toulouse
Blagnac" Meteo France station located 22 and $14 \mathrm{~km}$ from the Auradé and Lamasquère plots, respectively (Table 1). On an annual basis, no climatic anomalies were observed for both sites, with mean annual temperature and precipitation close to normals; except during the 2007 cropping season, where mean annual temperature was slightly warmer than normals, and less precipitation was observed at the Lamasquère site than normals. For the 3 cropping seasons, temperature, precipitation and wind speed were slightly lower at Lamasquère than at the Auradé plot, but trends were very similar (Fig. 1). On a quarterly basis, except for large precipitations observed in spring 2007, seasonal precipitation dynamics were not no well-marked. Precipitation was generally similar on both sites but with strong local differences caused by thunderstorm events (Fig. 1d). On a weekly basis, no major differences were observed for PPFD and $T_{\mathrm{a}}$ between the two sites. During the winter of 2006-2007, episodes with high elevated $T_{\mathrm{a}}$ were observed on both sites compared to the winter of 2005-2006. Main wind directions were similar at the two sites, but more scatter was observed at Lamasquère (Table 1). SWC in the first $30 \mathrm{~cm}$ of soil followed globally the same evolution for both sites except during 2006 summer because of irrigation at Lamasquère (Fig. 1c and d). Absolute values of SWC were higher at Lamasquère than at Auradé because of (1) a higher water retention capacity of the soil at Lamasquère due to higher clay content (Table 1 ) and (2) the proximity of the "Touch" river at Lamasquère. Therefore, this absolute difference did not necessarily induce a difference in soil water availability for plants.

\subsection{Crop growth and production}

For winter crops (rapeseed, triticale and winter wheat), growth started with germination in November and remained slow until March (Figs. 2 and 3). However, winter wheat growth in 2007 at Lamasquère started earlier than for the other winter crops due, almost certainly, to the high temperature episodes during winter 2006-2007 (Fig. 1). The same phenomenon was observed by Aubinet et al. (submitted for publication) for 2007 winter wheat at the Lonzée site in Belgium. Maximum growth was observed from late April to late May. PAI ${ }_{\max }$, (Table 2) and the maximum leaf biomass were reached between the end of April and the middle of May, followed by senescence. For rapeseed, total biomass corresponded to leaves until April but all leaves had fallen by early June, even if the stems were still photosynthetically active. During senescence, biomass was reallocated from leaves and stems to fruits (Fig. 3). For summer crops (maize and sunflower), growth started in late May. Aboveground biomass increase was relatively constant until the beginning of August for sunflower and the beginning of September for maize. For both summer crops, PAI was at its maximum in the middle of July (Fig. 2, Table 2). Maize was harvested early at the end of August, corresponding to the beginning of senescence, because it was used for silaging. For both winter and summer crops, PAI is a more relevant indicator of photosynthetic area than LAI because leaves are not the only photosynthetic organ. This was particularly true at the end of rapeseed development in early June 2005, with PAI values higher than $1.5 \mathrm{~m}^{2} \mathrm{~m}^{-2}$ and GEP values lower than $-8 \mathrm{~g} \mathrm{C} \mathrm{m}^{-2} \mathrm{~d}^{-1}$ even though LAI values were close to $0 \mathrm{~m}^{2} \mathrm{~m}^{-2}$, as explained above (Figs. 2 and 4). AGB ranged from $324 \pm 157 \mathrm{~g} \mathrm{C} \mathrm{m}^{-2}$ for Auradé sunflower in 2007 to $810 \pm 311 \mathrm{~g} \mathrm{C} \mathrm{m}^{-2}$ for Lamasquère maize in 2006 (Table 2). On average, AGB were $36 \%$ lower at Auradé than at Lamasquère, but Exp were 65\% lower at Auradé than at Lamasquère. This more important difference in Exp is linked to crop residues, which were 1.9 times higher at Auradé than at Lamasquère. This is 


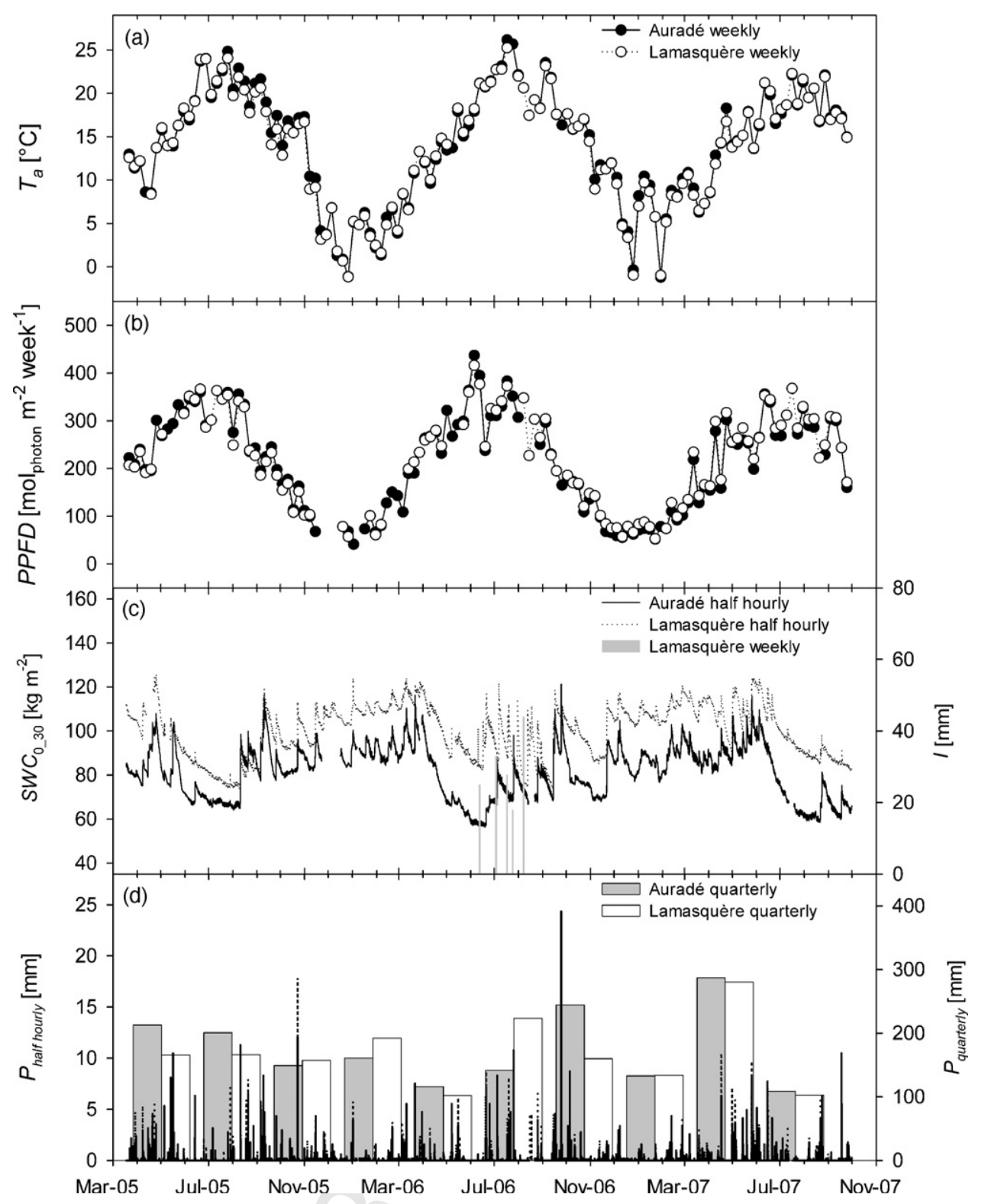

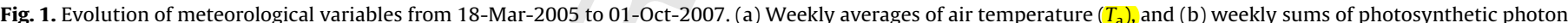

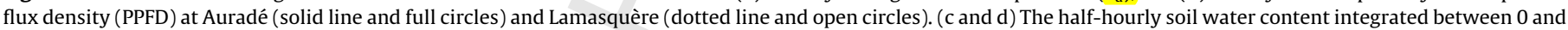

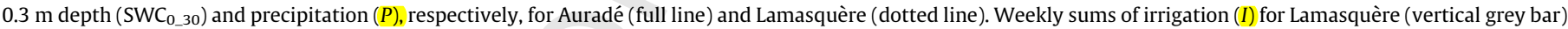
and the quarterly sums of precipitation for Auradé (grey bar) and Lamasquère (white bar) are also reported on graphs (c) and (d), respectively.

because Lamasquère is a cattle breeding farm exporting most of the aboveground biomass for cattle bedding and feeding, whereas Auradé is a cereal production farm exporting only the seeds. Residues were particularly low for maize in 2006 at Lamasquère because all aboveground biomass was used for silaging.

\subsection{Seasonal changes in carbon fluxes}

Net carbon fluxes over crop ecosystems are influenced by different processes; some are natural (photosynthesis and respiration), and others are caused by human activities (organic fertilization, tillage, ...). Fig. 4 presents the evolution of gross ecosystem production (GEP, i.e., ecosystem carbon uptake by both crop and weed photosynthesis) and ecosystem respiration $\left(R_{\mathrm{E}}\right.$, i.e., autotrophic and heterotrophic respiration). In order to separate the impacts of temperature from the other possible $R_{\mathrm{E}}$ driving variables (phenology, growth, water, management, etc.) the normalized ecosystem respiration at a reference temperature of $10^{\circ} \mathrm{C}\left(R_{10}\right)$ is also reported in Fig. 4 .

\subsubsection{Gross ecosystem production (GEP)}

The dynamics of GEP of the different crops were close to those of PAI (Figs. 2 and 4). For winter crops, GEP remained low like PAI until March, except for winter wheat in 2007 at Lamasquère. Indeed, winter wheat development occurred earlier in winter 2006-2007 because of the warm episodes described above. Therefore, absolute GEP values were high from December to March compared with winter wheat at Auradé in 2006. Overall, during crop development, absolute values of GEP increased to a maximum value $\left(\mathrm{GEP}_{\max }\right)$ corresponding to $\mathrm{PAI}_{\text {max }}$. Daily carbon fluxes at maximum crop development are reported in Table 2 for each crop. For winter crops, GEP $\max$ ranged between $-15.4 \mathrm{~g} \mathrm{C} \mathrm{m}^{-2} \mathrm{~d}^{-1}$ for rapeseed reached on 24May-2005 at Auradé and $-18.9 \mathrm{~g} \mathrm{C} \mathrm{m}^{-2} \mathrm{~d}^{-1}$ for winter wheat reached on 21-Apr-2007 at Lamasquère. These estimates agree 

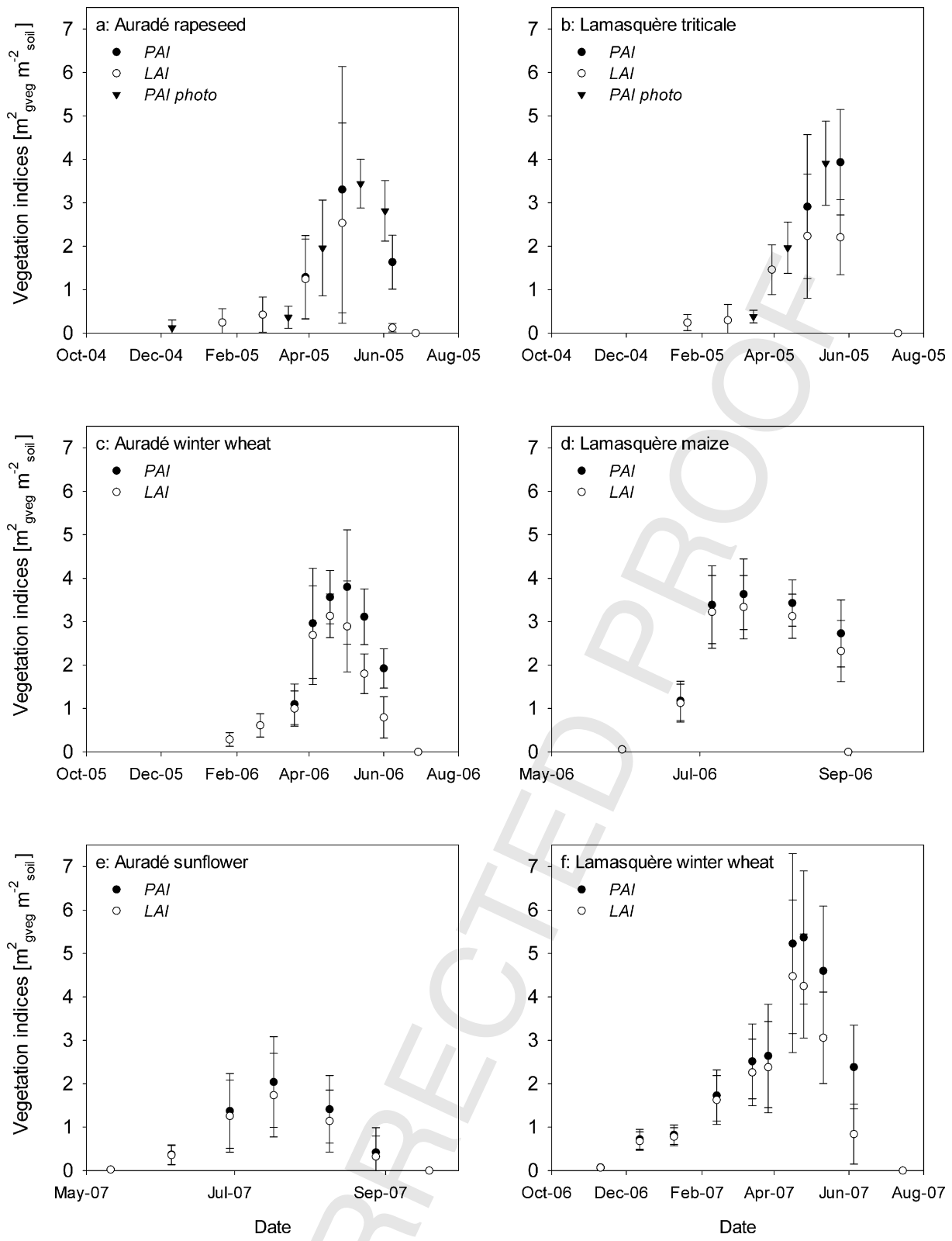

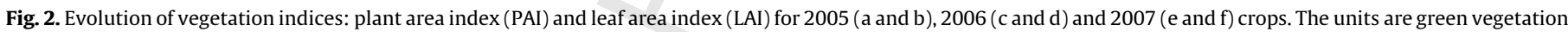

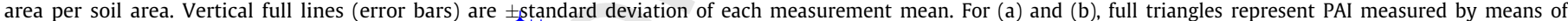
hemispherical photography (see Section 2.2.3).

with those reported over other winter wheat crops, $-17.4 \mathrm{~g} \mathrm{C} \mathrm{m}^{-2} \mathrm{~d}^{-1}$ and $-16.4 \mathrm{~g} \mathrm{C} \mathrm{m}^{-2} \mathrm{~d}^{-1}$ for the Ponca (USA) and Soroe (Denmark) sites, respectively (Falge et al., 2002), about $-16 \mathrm{~g} \mathrm{C} \mathrm{m}^{-2} \mathrm{~d}^{-1}$ at the Gebesee (Germany) site (Anthoni et al., 2004a) and $-15 \mathrm{~g} \mathrm{C} \mathrm{m}^{-2} \mathrm{~d}^{-1}$ at the Lonzée (Belgium) site (Aubinet et al., submitted for publication $)_{2}$. For maize, GEP $\max$ was $-19.6 \mathrm{~g} \mathrm{C} \mathrm{m}^{-2} \mathrm{~d}^{-1}$. Suyker et al. (2005) reported higher absolute GEP values of about $-27 \mathrm{~g} \mathrm{C} \mathrm{m}^{-2} \mathrm{~d}^{-1}$. However, GEP $\max$ per leaf area unit were higher at our site than in Suyker et al. (2005), with respective values of $5.8 \mathrm{~g} \mathrm{C} \mathrm{m}^{-2}$ leaves $\mathrm{d}^{-1}$ (maximum $\mathrm{LAI}=3.4 \mathrm{~m}^{2} \mathrm{~m}^{-2}$ ) and $4.5 \mathrm{~g} \mathrm{C} \mathrm{m}^{-2}$ leaves $\mathrm{d}^{-1}$ (maximum $\mathrm{LAI}=6 \mathrm{~m}^{2} \mathrm{~m}^{-2}$ ). The low $\mathrm{GEP}_{\max }$ observed at our site was probably not caused by physiological stress but by low LAI values. Moreover, the high $\mathrm{GEP}_{\max }$ per leaf area unit observed at our site could be interpreted as higher light use by the photosynthetic tissues caused by lower shadow effects at lower LAI. The difference in LAI can be explained by differences in irrigation. At our site, the irrigation amount was two times lower than in Suyker et al. (2005) (precipitation + irrigation during vegetation period were respectively 413 and $749 \mathrm{~mm}$ ). Verma et al. (2005) reported maximum LAI values of $3.9 \mathrm{~m}^{2} \mathrm{~m}^{-2}$ over rainfed maize with precipitation of $433 \mathrm{~mm}$ during the vegetation period, which is comparable to our study. Differences in maize variety (grain production in Suyker et al. (2005) and silaging at our site) and associated management practices might also explain LAI differences. Sunflower had the lowest absolute $\mathrm{GEP}_{\max }$ rate of $-13.7 \mathrm{~g} \mathrm{C} \mathrm{m}^{-2} \mathrm{~d}^{-1}$, probably because of the lower PAI of this crop $\left(\mathrm{PAI}_{\max }=2 \mathrm{~m}^{2} \mathrm{~m}^{-2}\right.$ ) compared to the others. Then crops entered into senescence, and the absolute values of GEP decreased until harvest. For maize, the interruption in carbon assimilation was sudden due to an early harvest just after the beginning of senescence. This event occurred so that the maize was used for silaging.

After harvest (see Section 2.1 and Fig. 5 for dates), absolute values of GEP often increased again due to the re-growth of seeds that fell during harvest and the growth of weeds under 

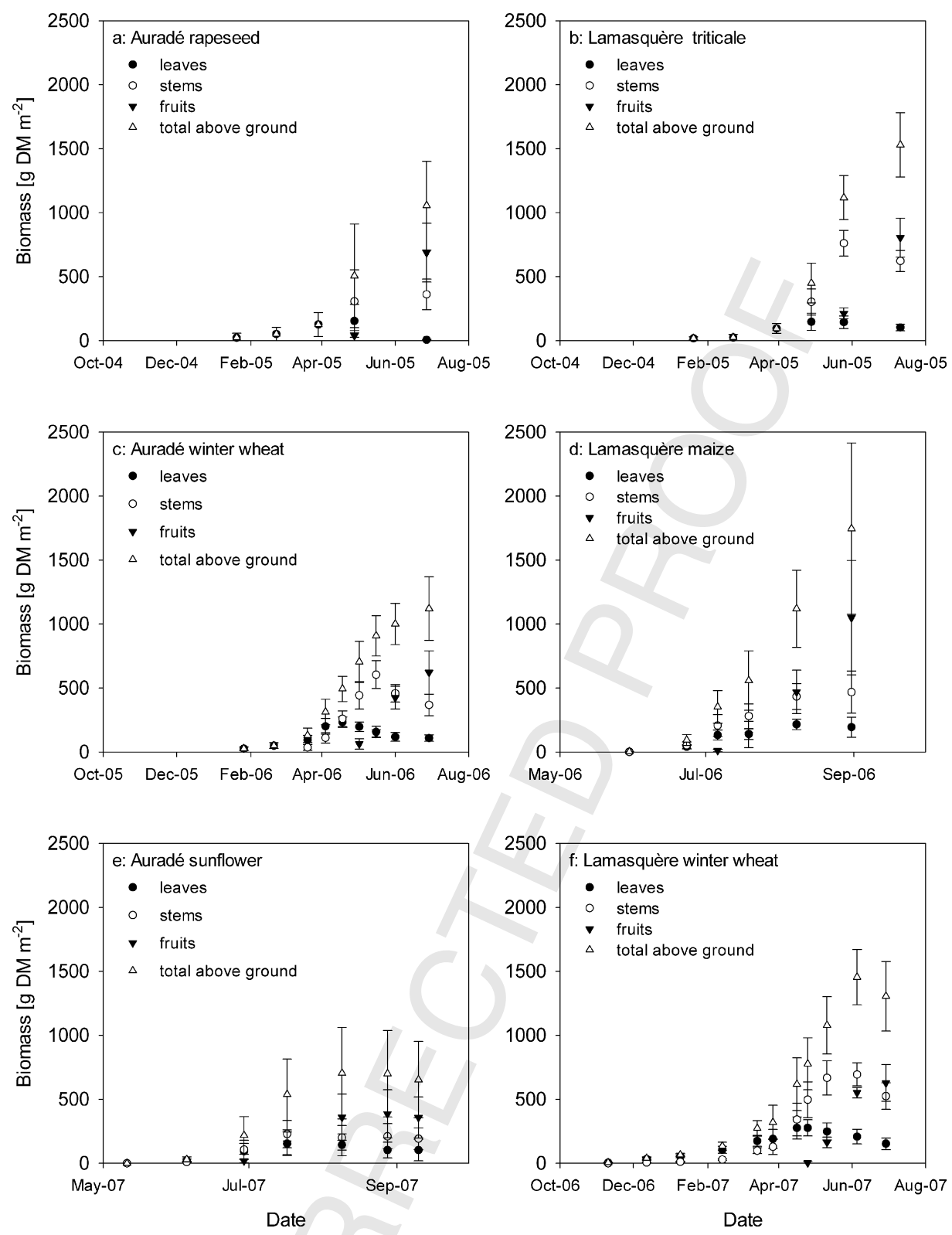

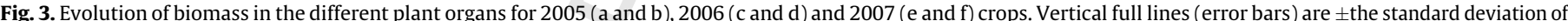

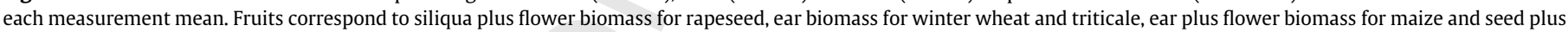
flower biomass for sunflower.

favourable meteorological conditions. A long re-growth period was observed at Lamasquère after the triticale harvest in 2005, with PAI values of about $0.7 \mathrm{~m}^{2} \mathrm{~m}^{-2}$ (estimate $\equiv$ with hemispherical photography) and GEP values reaching
$5.65 \mathrm{~g} \mathrm{C} \mathrm{m}^{-2} \mathrm{~d}^{-1}$ on 22-Oct-2005. Two other re-growth events occurred at Auradé at the end of summer and in fall 2005 with absolute GEP values smaller than for the Lamasquère re-growth. Re-growth was more important after 2005 crops than after 2006

\section{Table 2}

Values at the maximum of crop development of plant area index $\left(\mathrm{PAI}_{\max }\right)$, daily ecosystem respiration $\left(R_{\mathrm{E} \text { max }}\right)$ and gross ecosystem production (GEP $\left.\mathrm{max}_{\max }\right)$. Carbon content in the aboveground biomass (AGB) just before harvest, and in residue biomass and exported biomass (Exp) just after harvest were also reported. Values after the symbol \pm are the standard deviations from the mean.

\begin{tabular}{|c|c|c|c|c|c|c|}
\hline Sites & $\mathrm{PAI}_{\max }\left(\mathrm{m}^{2} \mathrm{~m}^{-2}\right)$ & $R_{\mathrm{E} \_\max }\left[\mathrm{g} \mathrm{C} \mathrm{m}^{-2} \mathrm{~d}^{-1}\right]$ & $\mathrm{GEP}_{\max }\left[\mathrm{g} \mathrm{C} \mathrm{m}^{-2} \mathrm{~d}^{-1}\right]$ & AGB $\left[\mathrm{g} \mathrm{C} \mathrm{m}^{-2}\right]$ & Residues $\left[\mathrm{g} \mathrm{C} \mathrm{m}^{-2}\right.$ ] & $\operatorname{Exp}\left[\mathrm{gC} \mathrm{m}^{-2}\right]$ \\
\hline \multicolumn{7}{|l|}{ Auradé } \\
\hline Rapeseed 2005 & $3.4 \pm 0.6$ & 8.0 & -15.4 & $482 \pm 158$ & $269 \pm 76$ & $213 \pm 61$ \\
\hline Winter wheat 2006 & $3.8 \pm 1.3$ & 7.0 & -15.6 & $516 \pm 115$ & $237 \pm 66$ & $279 \pm 42$ \\
\hline \multicolumn{7}{|l|}{ Lamasquère } \\
\hline Triticale 2005 & $3.9 \pm 1.2$ & 7.0 & -17.1 & $663 \pm 109$ & $158 \pm 41$ & $505 \pm 39$ \\
\hline Maize 2006 & $3.6 \pm 0.8$ & 11.0 & -19.6 & $810 \pm 311$ & $4 \pm 3$ & $806 \pm 57$ \\
\hline
\end{tabular}




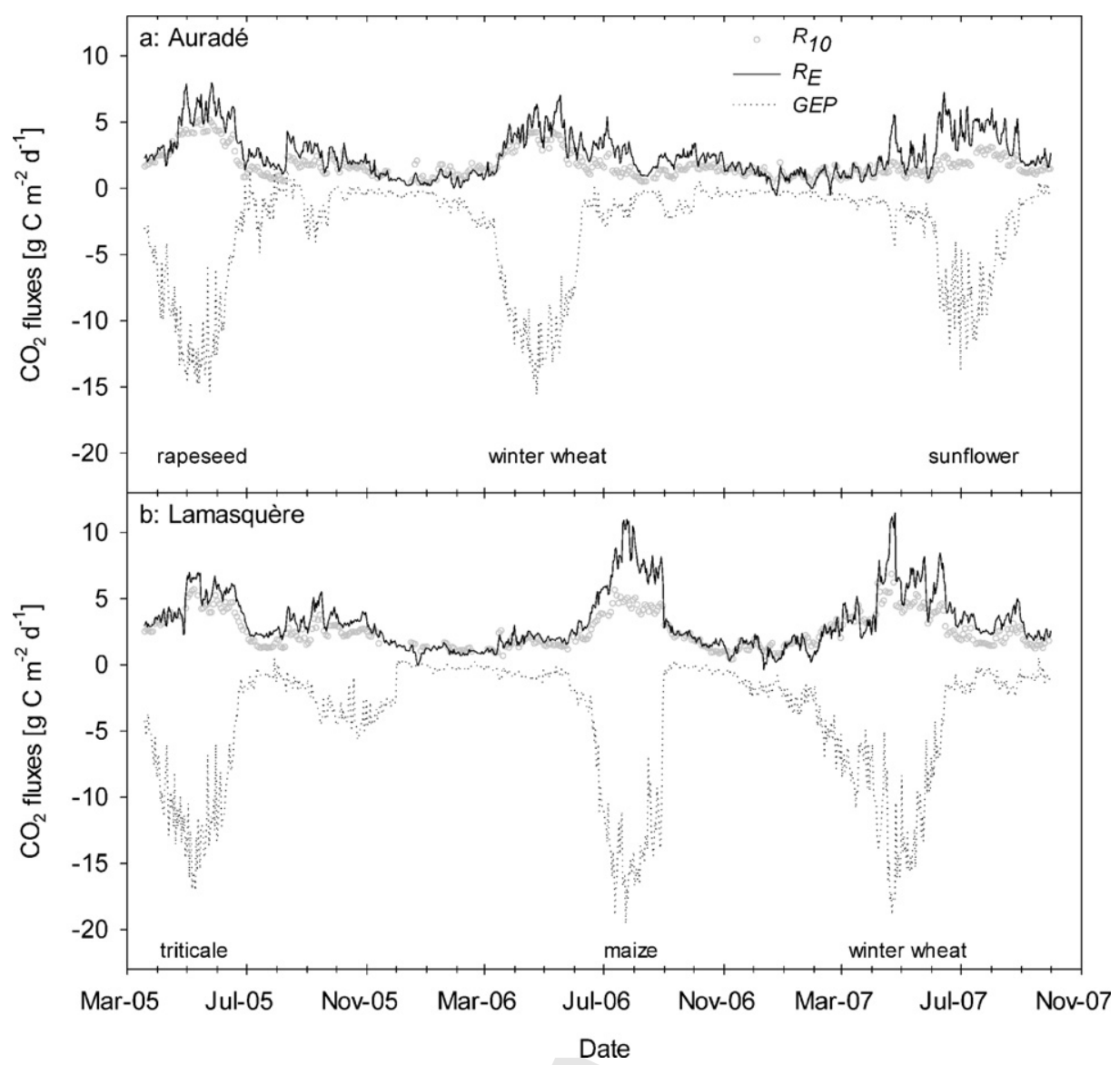

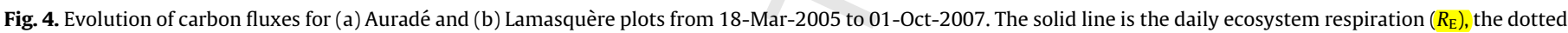

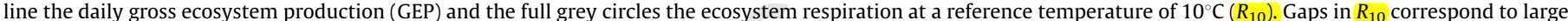

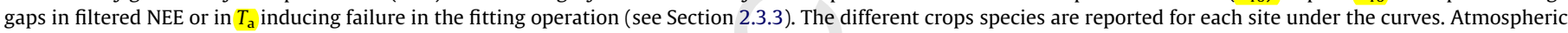
convention was used for this representation; fluxes from ecosystem to atmosphere are positives, and inversely, fluxes from atmosphere to ecosystem are negatives.

and 2007 crops because of important rainfall events and high temperatures in Fall 2005 (Fig. 1). After maize and sunflower crops, the stubbles were ploughed into the soil, and winter wheat was seeded; therefore, no re-growth was observed. For the other crops, re-growth was stopped by the different tillage operations (see Section 2.1 for dates). Low absolute GEP values during winter were caused by (1) low temperatures that reduced ecosystem activity for winter crops and (2) absence of vegetation during the winter and spring preceding the summer crop.

\subsubsection{Ecosystem respiration $\left(R_{E}\right)$}

$R_{\mathrm{E}}$ and $R_{10}$ seasonal dynamics were quite similar. This suggests that, at a seasonal scale, crop development is a more important driving variable for $R_{\mathrm{E}}$ than temperature. This hypothesis is confirmed by measurements at our sites showing that autotrophic respiration represents the largest proportion of $R_{\mathrm{E}}$ during vegetation periods (Sagnier and Le Dantec, personal communication). $R_{10}$ and $R_{\mathrm{E}}$ evolution differed more for summer crops probably because of high summer temperature affecting $R_{\mathrm{E}}$.

$R_{\mathrm{E}}$ globally followed the same dynamics as GEP and PAI during crop development. However, in spring $2005, R_{\mathrm{E}}$ was delayed compared to GEP. A sudden $R_{\mathrm{E}}$ increase occurred in late April, whereas absolute GEP had already increased. Lags between GEP and $R_{\mathrm{E}}$ dynamics have already been observed by Falge et al. (2002) in temperate deciduous and boreal coniferous forests. Both phenological and climatic factors could explain this lag. Heading and flower emergence are known to induce an increase in crop respiration (Baldocchi, 1994), and the late $R_{\mathrm{E}}$ increase occurred at this phenological stage. However, as $R_{\mathrm{E}}$ delay was not visible for 2006 and 2007 winter crops, this reinforces the fact that phenology was not the only factor. Low temperatures until late April followed by a rapid temperature increase and $45 \mathrm{~mm}$ of rainfall between 20 Apr-2005 and 01-May-2005 (Fig. 1) could have induced a sudden $R_{\mathrm{E}}$ increase. These two meteorological events can contribute to soil micro-organism activation and quickening of crop development. Maximum $R_{\mathrm{E}}$ values $\left(R_{\mathrm{E} \_ \text {max }}\right)$ for winter crops ranged between $7.0 \mathrm{~g} \mathrm{C} \mathrm{m}^{-2} \mathrm{~d}^{-1}$ on 17-May-2006 for winter wheat at Auradé and $11.5 \mathrm{~g} \mathrm{C} \mathrm{m}^{-2} \mathrm{~d}^{-1}$ on 24-Apr-2007 for winter wheat at Lamasquère. These observed values are higher than those reported in Falge et al. (2002) over two winter wheat plots $\left(3.1 \mathrm{~g} \mathrm{C} \mathrm{m}^{-2} \mathrm{~d}^{-1}\right.$ and $5.6 \mathrm{~g} \mathrm{C} \mathrm{m}^{-2} \mathrm{~d}^{-1}$ ), but agree with values of $8 \mathrm{~g} \mathrm{C} \mathrm{m}^{-2} \mathrm{~d}^{-1}$ reported by Aubinet et al. (submitted for publication) over a winter wheat crop. As $\mathrm{GEP}_{\text {max }}, R_{\mathrm{E}_{-} \max }$ estimated over maize in the present study was lower than the one $\left(13 \mathrm{~g} \mathrm{C} \mathrm{m}^{-2} \mathrm{~d}^{-1}\right)$ reported by Suyker et al. (2005), because of the LAI difference explained above.

During intercropping periods, $R_{\mathrm{E}}$ was relatively low at both sites, but peaks occurred. As these peaks affected both $R_{\mathrm{E}}$ and $R_{10}$, they were not controlled by temperature. Generally rainfall events, ploughing, residue incorporation into the soil and regrowth could explain these peaks. For example, $R_{\mathrm{E}}$ and $R_{10}$ increased in the beginning of August 2005 at Auradé, which occurred following incorporation of residues and plant regrowth into the soil by the cover crop on 04-Aug-2005 and a $55 \mathrm{~mm}$ rainfall event between 10-Aug-2005 and 11-Aug-2005. In the absence of vegetation on the plot at this time, this $R_{\mathrm{E}}$ increase could be explained by micro-organism activation caused by higher water and substrate availability for decom- 

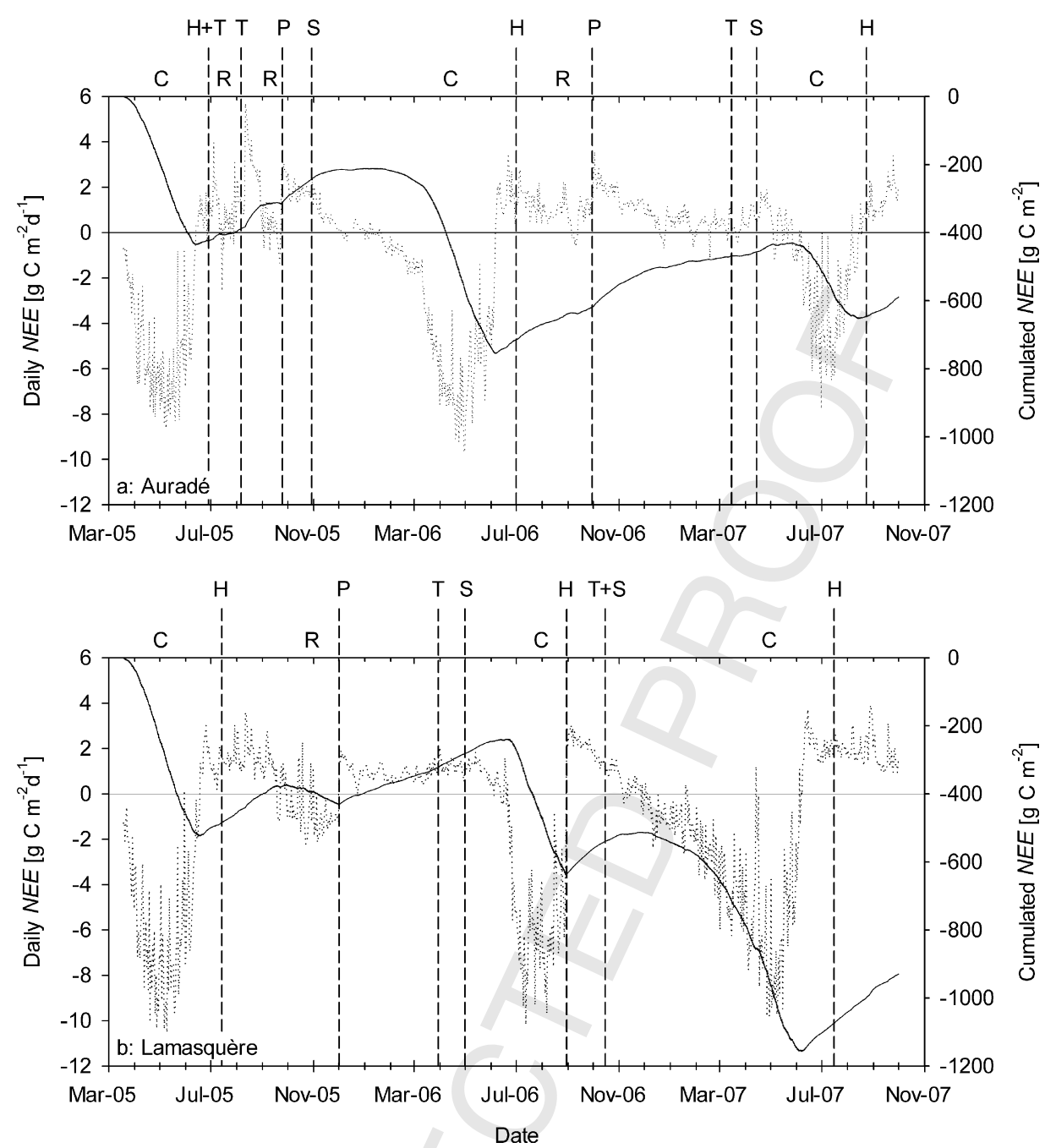

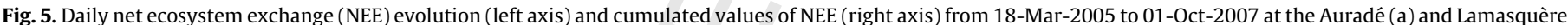

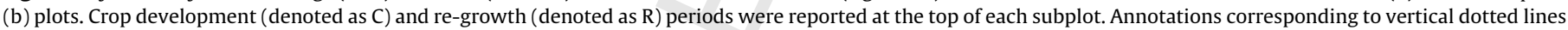

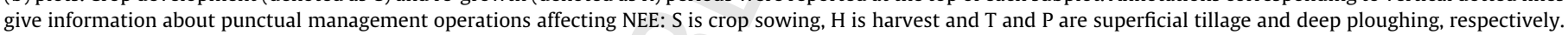

position. Generally, high $R_{\mathrm{E}}$ rates in summer after harvest in 2005 for both sites and in 2006 at Auradé were mainly caused by re-growth and soil water availability (Figs. 1 and 4 ).

\subsubsection{Net ecosystem exchange (NEE) and carbon storage dynamics}

NEE dynamics allow the determination of GEP and $R_{\mathrm{E}}$ importance in the ecosystem carbon dynamics, whereas cumulated NEE allows the identification of carbon storage or release periods (Fig. 5). A negative slope on the cumulated NEE curve means that the ecosystem behaves as a carbon sink (GEP $>R_{\mathrm{E}}$ ), and a positive slope means that the ecosystem behaves as a carbon source $\left(\mathrm{GEP}<R_{\mathrm{E}}\right)$. Overall, the dynamics were wellmarked with alternating carbon sequestration and carbon release periods corresponding to crop growth and bare soil, respectively. For the three observed seasons, Lamasquère was a stronger carbon sink than Auradé without considering management effects (see Section 3.5.2).

Development of crops (denoted C) appeared quite different for winter and summer crops. For winter wheat, NEE values were close to $0 \mathrm{~g} \mathrm{C} \mathrm{m}^{-2} \mathrm{~d}^{-1}\left(\mathrm{GEP}=R_{\mathrm{E}}\right.$ ) from the beginning of November until February at Auradé in 2006 and only until December at Lamasquère in 2007. Then, for all winter crops, NEE values became negative, and the ecosystem stored carbon until the beginning of June. Maximum absolute NEE values of $-8.6,-9.7,-10.5$ and $-9.8 \mathrm{~g} \mathrm{C} \mathrm{m}^{-2} \mathrm{~d}^{-1}$ were observed at Auradé for rapeseed and winter wheat and at Lamasquère for triticale and winter wheat, respectively. Between May and June, GEP decreased because senescence began, although $R_{\mathrm{E}}$ remained high; therefore, carbon storage became less important with decreasing absolute NEE values. In June, senescence was observed with a fast change in the sign of NEE, which became positive because $R_{\mathrm{E}}$ values became higher than absolute GEP values. For summer crops (maize and sunflower), NEE values were positive until June, about one and a half months after sowing. The NEE became negative and maximum absolute NEE values of -7.8 and $-10.2 \mathrm{~g} \mathrm{C} \mathrm{m}^{-2} \mathrm{~d}^{-1}$ were observed at Auradé for sunflower and at Lamasquère for maize, respectively. The ecosystem stored carbon from June to August for sunflower and from mid-June to harvest (denoted $\mathrm{H}$ ) for maize. The reversal from a carbon sink to a carbon source was more progressive for sunflower than for winter crops because of a slower senescence. For maize, the inversion was sudden because it was harvested, whereas it was still green just after the beginning of senescence.

Re-growth events (denoted $\mathrm{R}$ ) after harvest had visible effects on NEE and cumulated NEE. NEE decreased progressively, and occasionally negative NEE values were observed at Auradé in 2005 and 2006. During the 2005 re-growth event, the slope of cumulated NEE was close to 0 . Photosynthesis balanced soil and vegetation respiration during periods when only carbon losses from soil respiration should have occurred. The re-growth effect was even more important at Lamasquère because the ecosystem switched 
from a source to a sink. Negative NEE values down to $-2 \mathrm{~g} \mathrm{C} \mathrm{m}^{-2} \mathrm{~d}^{-1}$ were observed during re-growth events in 2005, and it allowed a net carbon storage of $-57 \mathrm{~g} \mathrm{C} \mathrm{m}^{-2}$.

Tillage (denoted $\mathrm{T}$ for superficial tillage and $\mathrm{P}$ for deep ploughing) affected the cumulated NEE in two ways, as described in Sections 3.3.1 and 3.3.2: (1) it stopped carbon assimilation from re-growth events, and (2) it could contribute to important soil respiration increases when associated with rainfall events and incorporation of plant residues as on 10-Aug-2005 at Auradé. Tillages before summer crops at Auradé and Lamasquère and the non-inverting tillage between maize and winter wheat at Lamasquère had no visible impact on NEE.

\subsection{NEE response to light}

Ecosystem net carbon fluxes of the different crops were compared in terms of response to light in order to evaluate the influence of climatic variables, species and sites on NEE as well as annual carbon balance.

\subsubsection{Climatic control on NEE response to light}

The VPD threshold above which NEE modelled by Eq. (8) were overestimated (see Section 2.3.5) was on average $27 \%$ lower for winter crops than for summer crops (Table 3). This shows that summer crops are more adapted to air high VPD than winter crops; their higher stomatal conductance was underlined by their higher net carbon fixation rate at high VPD.

Except for rapeseed at Auradé in 2005, the datasets were split into two parts according to light quality. The first one corresponded to the ratio of diffuse PPFD to total PPFD $(d / t)$ lower than 0.5 (clear sky conditions) and the other to $d / t$ higher than 0.5 (cloudy conditions). It can be seen that for aPPFD above $400 \mu \mathrm{mol} \mathrm{m}^{-2} \mathrm{~s}^{-1}, \mathrm{NEE}_{\mathrm{d}}$ values were higher for diffuse conditions (Fig. 6). Such observations have already been reported for many ecosystems (Alton et al., 2007; Gu et al., 2002; Law et al., 2002; Moureaux et al., 2006; Suyker et al., 2004). Considering all crops except rapeseed, the mean $\beta$ and $\alpha$ were higher $\left(-51 \mu \mathrm{mol} \mathrm{CO} \mathrm{m}^{-2} \mathrm{~s}^{-1}\right.$ and $-0.051 \mathrm{~mol} \mathrm{~mol}^{-1}$, respectively) in diffuse light conditions than in direct light conditions $\left(-33 \mu \mathrm{mol} \mathrm{CO} \mathrm{Cm}^{-2} \mathrm{~s}^{-1}\right.$ and $\left.-0.028 \mathrm{~mol} \mathrm{~mol}^{-1}\right)$. Large differences in parameterisation between diffuse and direct conditions were also observed by $\mathrm{Gu}$ et al. (2002) on different ecosystems (Scots pine forest, aspen forest, tallgrass prairie, mixed forest and wheat crops). Higher values of $\beta$ and $\alpha$ for diffuse light conditions were probably caused mainly by the limitation of shadow effects with a more homogeneous distribution of radiation among all leaves in plant canopies (Gu et al., 2002). It induced better light use efficiency for NEE and limited saturation effects.

The determination coefficient $\left(R^{2}\right)$ and the root mean square error (RMSE) were respectively 35\% higher and 37\% lower for cloudy conditions than for clear sky conditions. It was probably because aPPFD were usually higher for clear sky conditions, and this corresponds to the saturation part of the global light response curve. Therefore, aPPFD was probably not the most important driving variable influencing $\mathrm{NEE}_{\mathrm{d}}$ during clear sky conditions (Baldocchi, 1994); indeed, air and soil temperature and humidity, wind speed and measurement error are more important driving variables of $\mathrm{NEE}_{\mathrm{d}}$ in clear sky conditions.

\subsubsection{Species and site impact on NEE response to light}

Comparison of crop behaviours and fitting parameters in both clear sky and cloudy conditions (Fig. 6 and Table 3 ) shows that light saturation seems to be correlated to $\mathrm{PAI}_{\max }$ values (Table 2). Indeed, low $\beta$, as observed for sunflower at Auradé in 2007, correspond to low $\mathrm{PAI}_{\max }$ while high $\beta$, as observed for winter wheat at Lamasquère in 2007, correspond to high $\mathrm{PAI}_{\max }$. With similar aPPFD values in both cases, the lower the PAI is, the more

Table 3

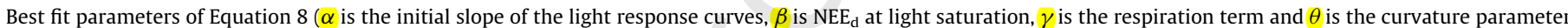

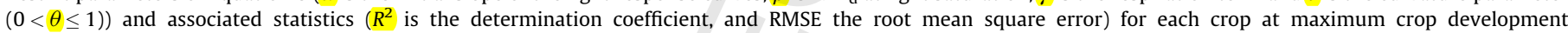

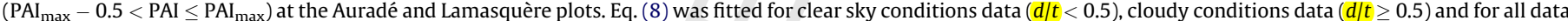

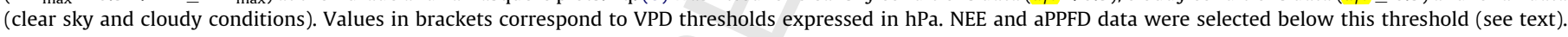

\begin{tabular}{|c|c|c|c|c|c|c|c|}
\hline \multirow[t]{2}{*}{ Data } & \multicolumn{4}{|l|}{ Parameters } & \multicolumn{3}{|c|}{ Statistics } \\
\hline & $\alpha\left[\mu \mathrm{mol} \mathrm{CO}_{2} \mu \mathrm{mol}_{\text {photon }}\right]$ & $\beta\left[\mu \mathrm{mol} \mathrm{CO}_{2} \mathrm{~m}^{-2} \mathrm{~s}^{-1}\right]$ & $\gamma\left[\mu \mathrm{mol} \mathrm{CO} \mathrm{m}^{-2} \mathrm{~s}^{-1}\right]$ & $\theta$ & $R^{2}$ & $\operatorname{RMSE}\left[\mu \mathrm{mol} \mathrm{CO} \mathrm{m}^{-2} \mathrm{~s}^{-1}\right]$ & $n$ \\
\hline \multicolumn{8}{|l|}{ All data } \\
\hline \multicolumn{8}{|l|}{ Auradé } \\
\hline Rapeseed 2005 (11) & -0.0670 & -38.43 & 4.39 & 0.63 & 0.88 & 3.54 & 568 \\
\hline Winter wheat 2006 (9) & -0.0410 & -33.52 & 2.42 & 0.90 & 0.86 & 3.71 & 504 \\
\hline Sunflower 2007 (14) & -0.0357 & -19.12 & 3.26 & 0.94 & 0.82 & 3.00 & 473 \\
\hline \multicolumn{8}{|l|}{ Lamasquère } \\
\hline Triticale 2005 (15) & -0.0548 & -52.77 & 4.46 & 0.00 & 0.79 & 4.66 & 307 \\
\hline Maize 2006 (17) & -0.0501 & -42.57 & 5.50 & 0.82 & 0.80 & 5.26 & 614 \\
\hline Winter wheat 2007 (10) & -0.0885 & -67.65 & 9.34 & 0.00 & 0.85 & 5.19 & 315 \\
\hline \multicolumn{8}{|l|}{ Diffuse/total $<0.5$} \\
\hline \multicolumn{8}{|l|}{ Auradé } \\
\hline Winter wheat 2006 & -0.0250 & -29.89 & 0.72 & 0.99 & 0.81 & 3.22 & 200 \\
\hline Sunflower 2007 & -0.0420 & -19.70 & 4.37 & 0.90 & 0.38 & 3.68 & 139 \\
\hline \multicolumn{8}{|l|}{ Lamasquère } \\
\hline Triticale 2005 & -0.0239 & -45.71 & 0.10 & 0.80 & 0.52 & 5.11 & 150 \\
\hline Maize 2006 & -0.0249 & -31.60 & 0.83 & 1.00 & 0.61 & 5.49 & 277 \\
\hline Winter wheat 2007 & -0.0229 & -36.97 & -1.20 & 1.00 & 0.59 & 5.68 & 103 \\
\hline \multicolumn{8}{|l|}{ Diffuse/total $>0.5$} \\
\hline \multicolumn{8}{|l|}{ Auradé } \\
\hline Winter wheat 2006 & -0.0444 & -37.86 & 2.71 & 0.90 & 0.92 & 3.03 & 304 \\
\hline Sunflower 2007 & -0.0398 & -28.01 & 3.42 & 0.70 & 0.87 & 2.54 & 334 \\
\hline \multicolumn{8}{|l|}{ Lamasquère } \\
\hline Triticale 2005 & -0.0510 & -55.76 & 4.39 & 0.31 & 0.86 & 3.71 & 157 \\
\hline Maize 2006 & -0.0486 & -51.55 & 5.34 & 0.87 & 0.90 & 3.93 & 337 \\
\hline Winter wheat 2007 & -0.0792 & -87.02 & 8.85 & 0.00 & 0.92 & 3.78 & 212 \\
\hline
\end{tabular}



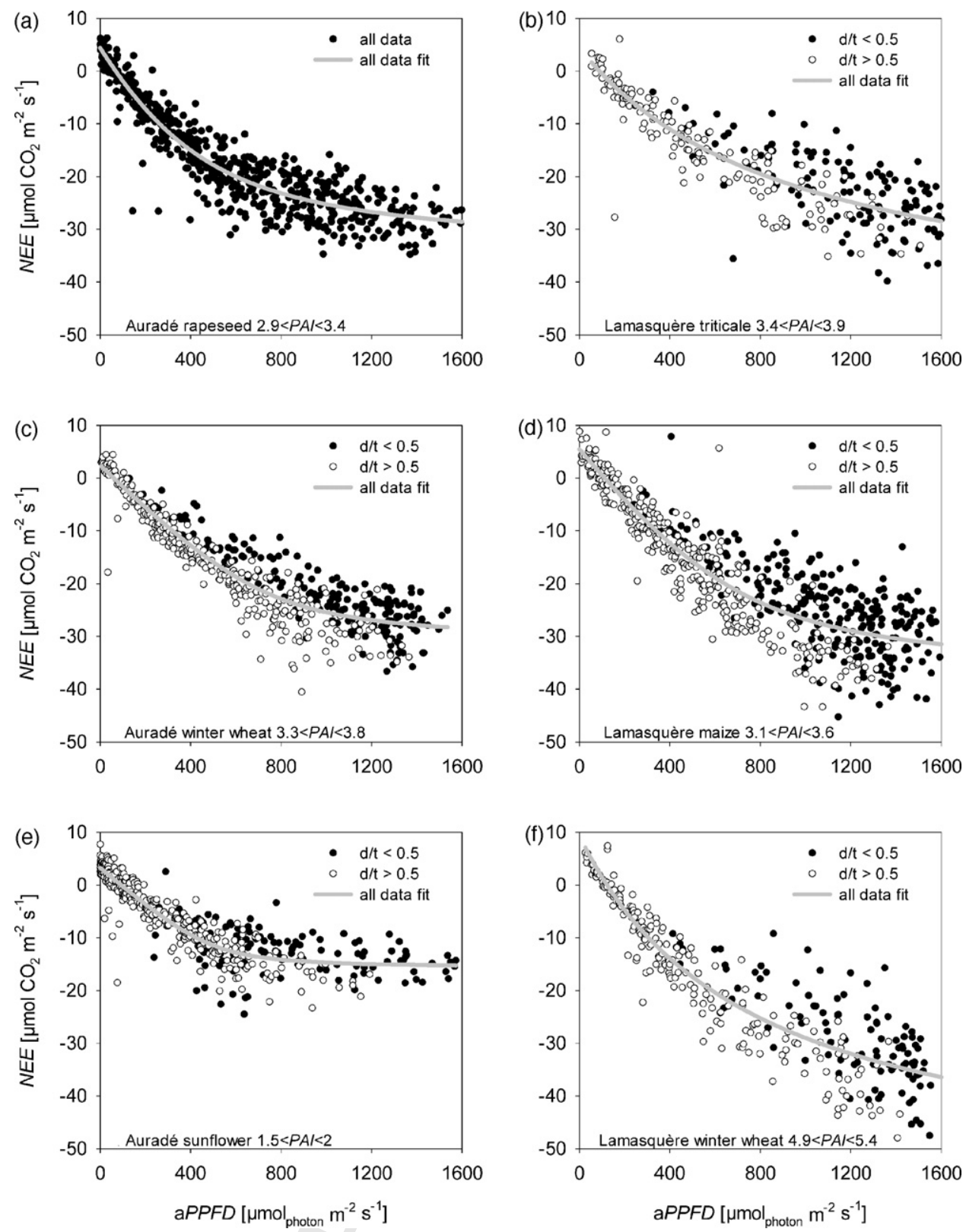

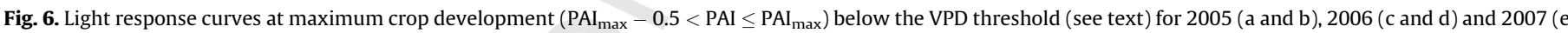

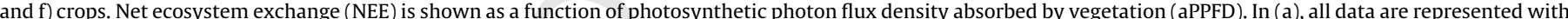

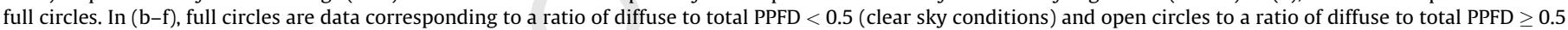

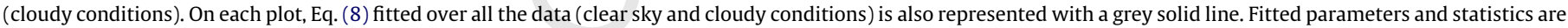
reported in Table 3.

light can easily penetrate deeply within the canopy, and the more light saturation can occur rapidly. Leaf orientation, which is planophile for sunflower (and almost erectophile for winter wheat), may also contribute to the earlier saturation of the crop at high solar incident angles due to more important shadows effects. This phenomenon also affected $\alpha$, which was $60 \%$ lower for sunflower than for Lamasquère 2007 winter wheat. For all other crops, PAI $_{\text {max }}$ were similar $\left(3.4 \mathrm{~m}^{2} \mathrm{~m}^{-2}<\mathrm{PAI}_{\max }<3.9 \mathrm{~m}^{2} \mathrm{~m}^{-2}\right)$. It is noteworthy that no marked differences in $\alpha$ and $\beta$ were observed between C3 winter crops (rapeseed, winter wheat and triticale) and the C4 summer crop (maize). Indeed, Baldocchi (1994) observed lower $\alpha$ values for maize than for winter wheat crop, but it was caused by lower PPFD absorbed by the maize canopy on their sites. In our case, aPPFD values were similar for both C3 winter crops and maize. This can be explained by: (1) $R_{\mathrm{E}}$ values being higher for maize than for $\mathrm{C} 3$ winter crops, resulting in a lower light use efficiency for maize at our site, as it was noted by Ruimy et al. (1995), (2) canopy architecture, as mentioned above, being more erectophile for winter wheat and triticale than for maize, (3) footprint mismatching between the flux measurements and PAI and $a P P F D$ measurements and (4) limitations of $N E E_{d}$ description quality by Eq. (8). Other factors, such as soil type, fertilization supply and inter-annual climate variability, could contribute to observed differences in crop carbon assimilation efficiency between sites and species, but they are difficult to assess here.

\subsection{Crop carbon balance}

\subsubsection{Annual net ecosystem production (NEP)}

For winter crops, NEP ranged from $-286 \pm 23 \mathrm{~g} \mathrm{C} \mathrm{m}^{-2} \mathrm{y}^{-1}$ for rapeseed in 2005 at Auradé to $-369 \pm 33 \mathrm{~g} \mathrm{C} \mathrm{m}^{-2} \mathrm{y}^{-1}$ for winter 
Table 4

Annual net ecosystem production (NEP) at different crop sites and for different crop species.

\begin{tabular}{|c|c|c|c|}
\hline Crop species & $\mathrm{NEP},\left(\mathrm{g} \mathrm{C}^{-2} \mathrm{y}^{-1}\right)$ & Site/Year & Reference \\
\hline \multicolumn{4}{|l|}{ Summer crops } \\
\hline Maize (mean value) & -576 & Bondville 1997, 1999, 2001 & Hollinger et al. (2005) \\
\hline Rainfed maize (mean value) & -454 & Mead 2001, 2002 & Verma et al. (2005) \\
\hline Irrigated maize (mean value) & -480 & Mead 2001-2003 & Verma et al. (2005) \\
\hline Maize (conventional and reduce tillage) & -290 to -300 & Rosemount 2003 & Baker and Griffis (2005) \\
\hline Maize & $-186 \pm 42$ & Lamasquère 2006 & This study \\
\hline Potato & -49 to 29 & Gebesee 2002 & Anthoni et al. (2004b) \\
\hline Soybean (conventional and reduce tillage) & -50 to -85 & Rosemount 2002 & Baker and Griffis (2005) \\
\hline Soybean (mean value) & -33 & Bondville 1998, 2000, 2002 & Hollinger et al. (2005) \\
\hline Soybean (mean value) & 18 to 48 & Mead 2002 & Verma et al. (2005) \\
\hline Spring barley & 210 & Jokioinen 2001 & Lohila et al. (2004) \\
\hline Sugar beet & -610 & Lonzée 2004 & Moureaux et al. (2006) \\
\hline Sunflower & $28 \pm 18$ & Auradé 2007 & This study \\
\hline \multicolumn{4}{|l|}{ Winter crops } \\
\hline Rapeseed & $-286 \pm 23$ & Auradé 2005 & This study \\
\hline Triticale & $-335 \pm 42$ & Lamasquère 2005 & This study \\
\hline Winter wheat & -183 & Ponca 1997 & Falge et al. (2001) \\
\hline Winter wheat & -185 to -245 & Gebesee 2001 & Anthoni et al. (2004a) \\
\hline Winter wheat & $-324 \pm 20$ & Auradé 2006 & This study \\
\hline Winter wheat & $-369 \pm 33$ & Lamasquère 2007 & This study \\
\hline \multicolumn{4}{|l|}{ One year rotation } \\
\hline Winter wheat + maize & -197.6 & Yucheng 2003 & Jun et al. (2006) \\
\hline Winter wheat + maize & -317.9 & Yucheng 2004 & Jun et al. (2006) \\
\hline
\end{tabular}

wheat in 2007 at Lamasquère (Table 4). Despite its large annual GEP, maize NEP was only $-186 \pm 42 \mathrm{~g} \mathrm{C} \mathrm{m}^{-2} \mathrm{y}^{-1}$. The ratio of annual GEP to annual $R_{\mathrm{E}}$, denoted $v$, allows the determination of the respective contribution of crop carbon assimilation by photosynthesis and ecosystem respiration to NEP (Falge et al., 2002). The mean value of $v$ for winter crops was 1.34 . For maize, $v$ was $13 \%$ lower than for winter crops $(v=1.17)$. However, annual GEP were similar in both cases $\left(-1310 \mathrm{~g} \mathrm{C} \mathrm{m}^{-2} \mathrm{y}^{-1}\right.$ on average for winter crops and $-1286 \mathrm{~g} \mathrm{C} \mathrm{m}^{-2} \mathrm{y}^{-1}$ for maize). The difference in $v$ was therefore explained by the large observed difference in annual $R_{\mathrm{E}}$ (982 $\mathrm{g} \mathrm{C} \mathrm{m}^{-2} \mathrm{y}^{-1}$ on average for winter crops and $1100 \mathrm{~g} \mathrm{C} \mathrm{m}^{-2} \mathrm{y}^{-1}$ for maize). Sunflower was a carbon source on an annual basis with a NEP of $28 \pm 18 \mathrm{~g} \mathrm{C} \mathrm{m}^{-2} \mathrm{y}^{-1}(v=0.97)$. This low value compared to maize is the result of a low annual GEP of $-803 \mathrm{~g} \mathrm{C} \mathrm{m}^{-2} \mathrm{y}^{-1}$ and $R_{\mathrm{E}}$ of $831 \mathrm{~g} \mathrm{C} \mathrm{m}^{-2} \mathrm{y}^{-1}$. We suggest that NEP differences observed among winter crops and among summer crops were mostly due to differences in crop carbon assimilation efficiency (see Section 3.4) and to year to year climatic variations. However, these factors could not fully explain NEP differences between winter and summer crops. At our sites, summer crop NEP values were in absolute 76\% lower than winter crops. It is therefore important to consider the season length of carbon assimilation. For 2006 and 2007 crops, the season length of carbon assimilation was calculated as the number of days between sowing and harvest with negative daily NEE. It was not calculated for 2005 crops, because flux measurements started after the beginning of the season of carbon assimilation. The season length was 53\% shorter for summer crops (76 and 86 days for maize and sunflower, respectively) than for winter crops (156 and 189 days for winter wheat in 2006 at Auradé and 2007 at Lamasquère, respectively). The season length was particularly long for 2007 winter wheat at Lamasquère because of the warm 2007 winter. This emphasizes the fact that long bare soil periods can counteract the ecosystem carbon storage on an annual basis by carbon losses through heterotrophic respiration. Compared to NEP values found at other instrumented crop sites (Table 4), NEP values obtained at our site were on the same order of magnitude but with some noticeable differences. Absolute NEP values were $44 \%$ and $35 \%$ lower for winter wheat at the Ponca and Gebesee sites, respectively, (Anthoni et al., 2004a; Falge et al., 2001) than for the mean NEP of our winter crops. It may be explained by differences in climate, which is more continental and with lower temperatures at these two sites compared to our oceanic climate and therefore conducive to lower ecosystem productivity. The low LAI and early harvest of maize resulted in a 59\% lower NEP in our study compared with values found in the literature (Baker and Griffis, 2005; Hollinger et al., 2005; Verma et al., 2005). Sunflower NEP was comparable with low carbon assimilation rates encountered for soybean (Baker and Griffis, 2005; Hollinger et al., 2005; Verma et al., 2005 ) and potato (Anthoni et al., 2004b) with NEP close to neutral. The stronger sink of carbon was observed at the Lonzée sugar beet crop in Belgium (Moureaux et al., 2006) and the stronger source at the Jokioinen spring barley crop in Finland (Lohila et al., 2004). For the Chinese site of Yucheng (Jun et al., 2006), carbon storage seemed a bit low compared to all the other sites because two crops (winter wheat and maize) were cultivated in one year; therefore, bare soil periods were limited. However, this comparison between sites is relatively uncertain because of differences in dates concerning the beginning and the end of the period use for annual NEP calculation, which were sometimes not explicitly reported. It is therefore important to harmonize and specify it for future NEP inter-comparisons exercises.

NEP uncertainty $(2 \sigma(\mathrm{NEP}))$ estimated in the present study ranged between $\pm 18 \mathrm{~g} \mathrm{C} \mathrm{m}^{-2} \mathrm{y}^{-1}$ for sunflower at Auradé and $\pm 42 \mathrm{~g} \mathrm{C} \mathrm{m}^{-2} \mathrm{y}^{-1}$ for triticale and maize at Lamasquère. This estimation of NEP uncertainty is in the same range of values as those reported in the Baldocchi (2003) review over different sites. In that study, NEP uncertainty ranged from $\pm 30 \mathrm{~g} \mathrm{C} \mathrm{m}^{-2} \mathrm{y}^{-1}$ at Harvard forest to $\pm 68 \mathrm{~g} \mathrm{C} \mathrm{m}^{-2} \mathrm{y}^{-1}$ for a short bog with different estimations methods. Dragoni et al. (2007) calculated an uncertainty in NEP caused by measurements' random error with a Monte Carlo simulation approach that varied between \pm 10 and $\pm 12 \mathrm{~g} \mathrm{C} \mathrm{m}^{-2} \mathrm{y}^{-1}$. These results were very close to our uncertainty in NEP caused by measurements' random error that varied between \pm 4 and $\pm 7 \mathrm{~g} \mathrm{C} \mathrm{m}^{-2} \mathrm{y}^{-1}$ at our sites. Richardson and Hollinger (in press,) used a similar approach than in the present study to estimate NEP uncertainty due to measurements random error and to long gaps in the data set. These authors found results very close to our global uncertainty estimate, ranging between \pm 25 and $\pm 44 \mathrm{~g} \mathrm{C} \mathrm{m}^{-2} \mathrm{y}^{-1}$ at different forest sites. Independent of the method used, NEP uncertainty estimates seem relatively stable across different sites.

Table 5 reports the impacts of methodology on NEP calculation. Differences in NEP were very limited and were always in the 
Table 5

Methodology impacts on net ecosystem production (NEP). NEP was calculated with the methodology describe in the present study (see Section 2.3 for methodology details), with the application of a conventional steady state test with no absolute threshold (A), with fixed periods of 90 days that affect both $u *$ threshold detection and gapfilling $(\mathrm{B})$, with a calculation of the storage term $\left(F_{\mathrm{cs}}\right)$ from one point of the $\mathrm{CO}_{2}$ concentration measurement $(\mathrm{C})$ and with the simultaneous application of $\mathrm{A}, \mathrm{B}$ and $C$. Units are $\mathrm{g} \mathrm{C} \mathrm{m}^{-2} \mathrm{y}^{-1}$.

\begin{tabular}{|c|c|c|c|c|c|}
\hline Site/Year & This study & $\begin{array}{l}\text { A: fixed } \\
\text { 90-day } \\
\text { periods }\end{array}$ & $\begin{array}{l}\text { B: conventional } \\
\text { stationarity }\end{array}$ & $\begin{array}{l}\mathrm{C}: F_{\mathrm{cs}} \\
\text { from } 1 \\
\text { point }\end{array}$ & $A+B+C$ \\
\hline \multicolumn{6}{|l|}{ Auradé } \\
\hline 2005 & $-286 \pm 22$ & $-295 \pm 22$ & $-277 \pm 21$ & $-286 \pm 22$ & $-287 \pm 22$ \\
\hline 2006 & $-324 \pm 20$ & $-319 \pm 19$ & $-313 \pm 19$ & $-324 \pm 20$ & $-307 \pm 19$ \\
\hline 2007 & $28 \pm 18$ & $24 \pm 18$ & $36 \pm 19$ & $31 \pm 20$ & $33 \pm 19$ \\
\hline \multicolumn{6}{|c|}{ Lamasquère } \\
\hline 2005 & $-335 \pm 42$ & $-352 \pm 29$ & $-331 \pm 41$ & $-335 \pm 42$ & $-342 \pm 28$ \\
\hline 2006 & $-186 \pm 42$ & $-204 \pm 34$ & $-182 \pm 36$ & $-194 \pm 37$ & $-192 \pm 30$ \\
\hline 2007 & $-369 \pm 33$ & $-389 \pm 27$ & $-362 \pm 36$ & $-375 \pm 33$ & $-381 \pm 27$ \\
\hline
\end{tabular}
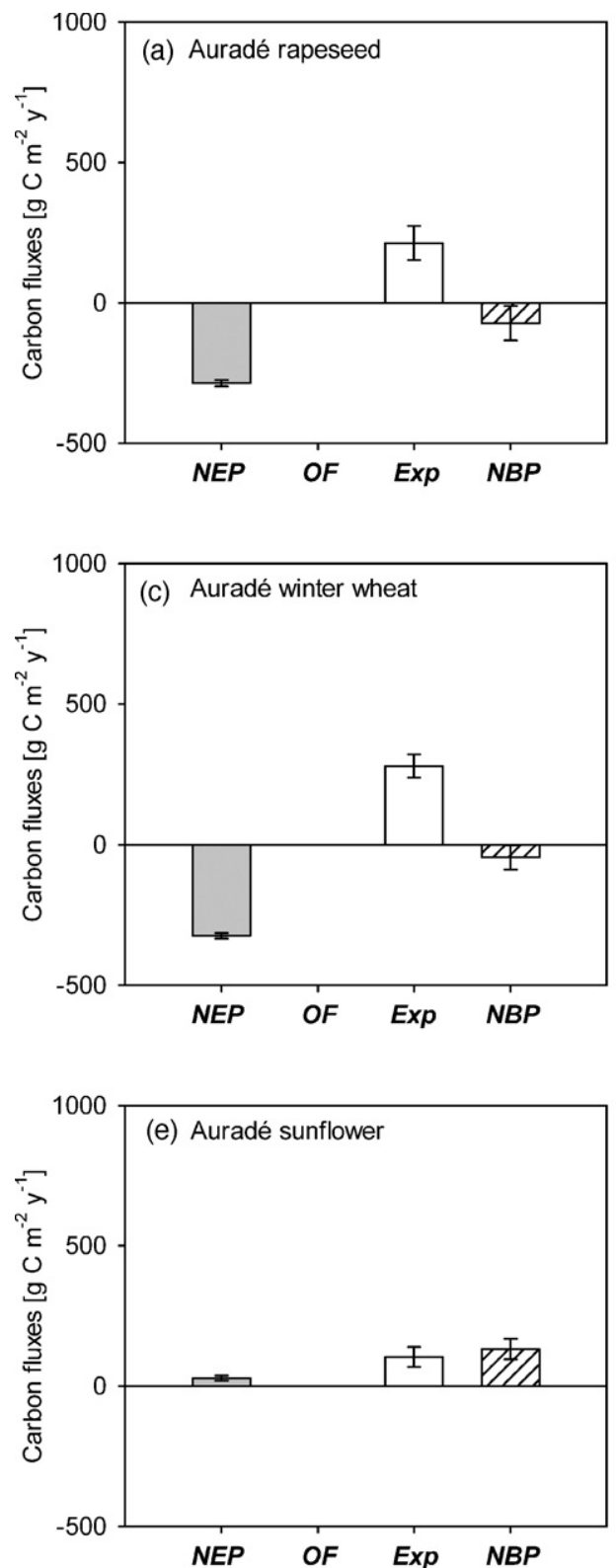

uncertainty range. However, NEP calculated with the conventional steady state test were systematically higher than those calculated with our modified steady state test. As it is explained in Section 2.3.2, the conventional steady state test might failed when NEE is close to 0 for mathematical reasons. Therefore, when considering bare soil periods with a low respiration rate, NEE close to 0 were discarded and replaced by gapfilled data from higher positive NEE values. It resulted in a systematic overestimation of NEP. The effect of applying fixed periods of 90 days (Reichstein et al., 2005) instead of CFP for the determination of $u *$ threshold and gapfilling procedures is not obvious. In most cases, using 90-day periods resulted in a slight underestimation of NEP. The most critical management event that modified roughly instantaneous carbon fluxes were harvest and tillage operations. Thus, the impact on NEP should therefore depend on how the CFP and 90-day periods mismatch. Impact of $F_{\mathrm{cs}}$ calculation from one point measurement of $\mathrm{CO}_{2}$ concentration is only noticeable for 2007 NEP at Auradé and
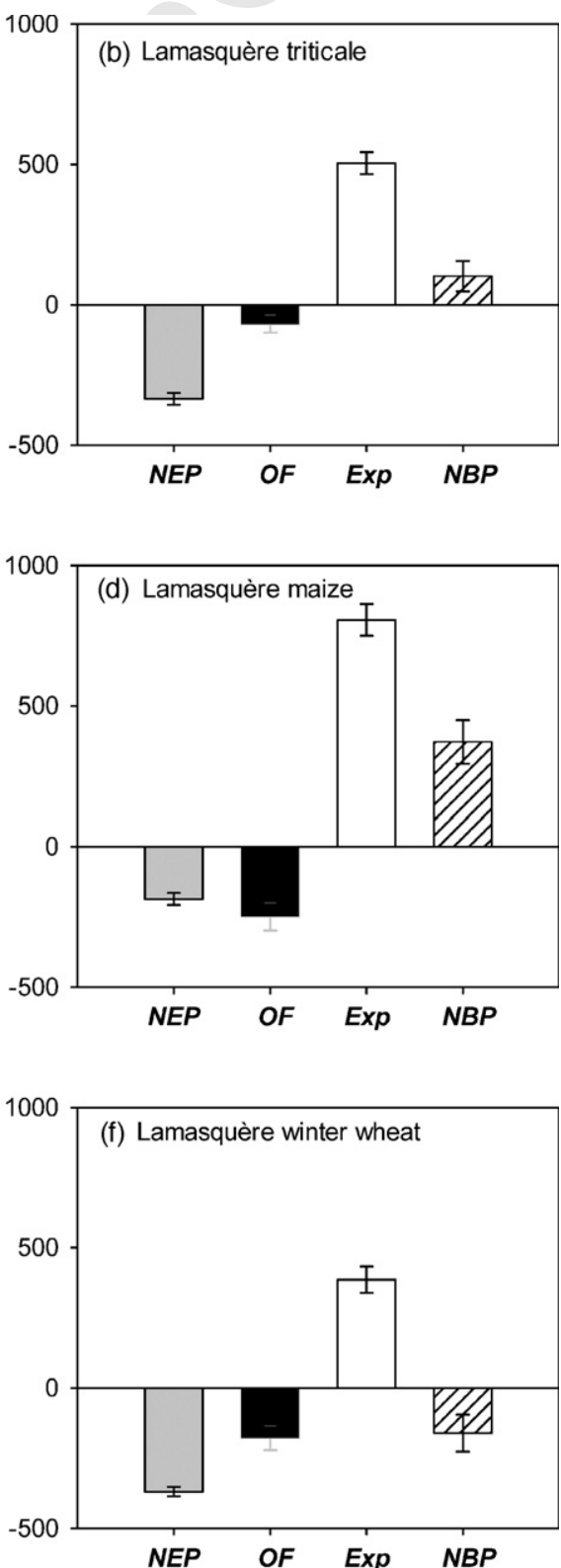

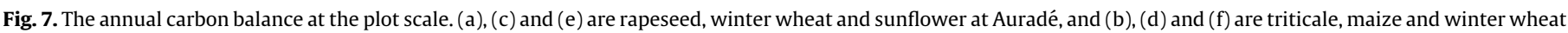

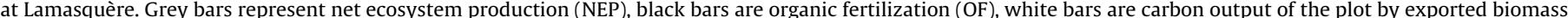

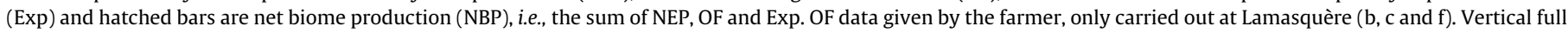
lines (error bars) are \pm the standard deviation of each variable. 
for 2006 and 2007 NEP at Lamasquère when $\mathrm{CO}_{2}$ concentration profile was installed. In theory, as gaps in filtered NEE occurred mostly at night (53\% of gap on average for both sites) when $F_{\mathrm{cs}}$ is important, calculation of $F_{\mathrm{cs}}$ from one point should result in an underestimation of NEP. Mean diurnal variation of half-hourly $F_{\mathrm{cs}}$ data was 2.6 times higher at Lamasquère than at Auradé (not shown). At Auradé $F_{\mathrm{cs}}$ was relatively low because of the slight slope at this site, which may induce horizontal advection during low turbulence conditions. Thus, a slight NEP underestimation was observed at Lamasquère in 2006 and 2007 but not at Auradé in 2007. Finally, the compensation phenomenon when applying the conventional steady state test, fixed 90-day periods and $F_{\mathrm{cs}}$ calculation from one point all together resulted in no systematic differences in NEP.

\subsubsection{Management impacts on annual carbon balance}

For the six crops, annual NBP ranged from a significant carbon sink of $-161 \pm 66 \mathrm{~g} \mathrm{C} \mathrm{m}^{-2} \mathrm{y}^{-1}$ for winter wheat at Lamasquère in 2007 to a strong carbon source of $372 \pm 78 \mathrm{~g} \mathrm{C} \mathrm{m}^{-2} \mathrm{y}^{-1}$ for maize at Lamasquère in 2006 (Fig. 7). Marked differences in NBP were observed between the two crop sites, Auradé and Lamasquère. First, OF at Lamasquère was an important carbon input ranging from $-68 \pm 31$ to $-249 \pm 49 \mathrm{~g} \mathrm{C} \mathrm{m}^{-2} \mathrm{y}^{-1}$. As a consequence, carbon inputs $(\mathrm{NEP}+\mathrm{OF})$ were on average $58 \%$ lower at Auradé than at Lamasquère, whereas NEP were only $35 \%$ lower. However, Lamasquère carbon exportations were 2.8 times higher than Auradé Exp (Table 2). As a consequence, for 2005 and 2006 crops, NBP were negative at Auradé and positive at Lamasquère. For sunflower in 2007 at Auradé, positive NEP resulted in a source of carbon of $132 \pm 37 \mathrm{~g} \mathrm{C} \mathrm{m}^{-2} \mathrm{y}^{-1}$ considering Exp. The significant carbon sink for the winter wheat in 2007 at Lamasquère may be explained in two ways: (1) absolute NEP was the highest observed of the six crops, and (2) Exp was less important compared to 2005 and 2006 at Lamasquère (residues was more than 2 times higher in 2007 than the mean of 2005 and 2006). However, the ratio of -NEP to Exp was equal to 0.96 for winter wheat at Lamasquère in 2007, meaning that the plot was a carbon sink only because of OF. For 2005 and 2006 crops, the ratio of -NEP to Exp was 1.34 and 1.16 for rapeseed and winter wheat at Auradé, respectively, and 0.66 and 0.23 for triticale and maize at Lamasquère, respectively. This reveals the strong impact of biomass exportation on NBP for these 2 years.

In the USA, it has been shown that maize/soybean rotation had NBP close to neutrality: some studies found non-significant low carbon sinks (Baker and Griffis, 2005; Dobermann et al., 2006; Hollinger et al., 2005, 2006), and others non-significant low carbon sources (Grant et al., 2007; Verma et al., 2005). These differences were mostly due to management practices (irrigation, tillage,...). These results are comparable to those found at Aurade with a carbon balance for the 3 years close to neutrality. At Lamasquère, the mean NBP for the 3 years was about $100 \mathrm{~g} \mathrm{C} \mathrm{m}^{-2} \mathrm{y}^{-1}$; therefore, this site is a carbon source. Similar observations have been made in other agrosystems. Anthoni et al. (2004a) found that winter wheat crop was a significant carbon source with a NBP between 45 and $105 \mathrm{~g} \mathrm{C} \mathrm{m}^{-2} \mathrm{y}^{-1}$. Similar carbon sources were reported in north China by Jun et al. (2006) over 2 one-year winter wheat/maize rotations with NBP between 108 and $341 \mathrm{~g} \mathrm{C} \mathrm{m}^{-2} \mathrm{y}^{-1}$. For a four years rotation of sugar beat/winter wheat/potato/winter wheat, Aubinet et al. (submitted for publication) observed a slighter mean NBP of $42 \mathrm{~g} \mathrm{C} \mathrm{m}^{-2} \mathrm{y}^{-1}$. However, they concluded that the large climatic difference in 2007 led to an underestimation of NBP; therefore, they computed a NBP of $90 \mathrm{~g} \mathrm{C} \mathrm{m}^{-2} \mathrm{y}^{-1}$ by substituting 2007 data with 2005 data. Grant et al. (2007) confirmed all these results for NBP by a modelling approach over 100 years, showing that carbon storage potential in agro-ecosystem soils is limited.

In the present study, larger uncertainties were observed for NBP than for NEP, and they were mostly due to important uncertainties in Exp and in OF. Therefore, we recommended that careful biomass sampling and regular OF analysis should be done to limit these uncertainties, even if these manipulations are very fastidious and time consuming.

\section{Summary and conclusions}

Carbon fluxes and the carbon balance of a succession of three crops were analysed at two cropland sites in South West France using the EC method and biomass sampling. With special care concerning the method of flux computation and correction adapted for croplands, NEE was partitioned into GEP and $R_{\mathrm{E}}$ and integrated over the year to compute NEP and NBP. We observed that the carbon flux dynamics were strongly correlated to crop development at the two sites. Winter crops had an earlier and a longer vegetation period than summer crops. However, interannual climate variability affected these dynamics. For example, winter wheat at Lamasquère in 2007 had an elevated winter development caused by exceptionally warm conditions. Another factor that had a strong impact on carbon fluxes was management practices. We observed that re-growth events could limit the carbon release of the ecosystem by introducing negative NEE values during periods when respiration should be the only cause of carbon fluxes. Tillage limited carbon storage, avoiding regrowth, and, if associated with rainfalls, it increased $R_{\mathrm{E}}$, by supplying substrate and enhancing micro-organism decomposition activity. Without these conditions, tillage effects on carbon fluxes were less obvious at our sites. NEE light response curves revealed differences in crops carbon assimilation. Both climatic (light intensity and quality, VPD, etc.) and plant species (PAI, plant architectures, physiology, etc.) variables affected this response in different ways and therefore introduced differences in NEP and NBP. Moreover, these variables can be correlated to and affected by management practices like fertilization and by site specificities.

NEP ranged between $-369 \pm 33 \mathrm{~g} \mathrm{C} \mathrm{m}^{-2} \mathrm{y}^{-1}$ for winter wheat at Lamasquère in 2007 and $28 \pm 18 \mathrm{~g} \mathrm{C} \mathrm{m}^{-2} \mathrm{y}^{-1}$ for sunflower at Auradé in 2007. Higher absolute NEP values for winter crops than for summer crops were observed, due to the longer season length for carbon assimilation. Differences within winter or summer crops were thought to be due mostly to year to year climate variability and differences in crop species. At the annual scale, we showed that the methodology impact on NEP was less than our uncertainty estimations; however, using the conventional stationarity test without an absolute threshold could lead to a systematic overestimation of NEP. Finally, NBP were calculated for each crop by adding carbon inputs through organic fertilizers and carbon outputs through biomass exportation to NEP. For the three years, the Auradé NBP indicate a nearly carbon balanced ecosystem, whereas the Lamasquère NBP of about $100 \mathrm{~g} \mathrm{C} \mathrm{m}^{-2} \mathrm{y}^{-1}$ indicates that the ecosystem was a carbon source. Moreover, carbon inputs through organic fertilizers could induce important $\mathrm{CH}_{4}$ and $\mathrm{N}_{2} \mathrm{O}$ emissions, which are stronger greenhouse gases than $\mathrm{CO}_{2}$. Therefore, a complete greenhouse gas budget at the plot scale should be investigated to fully evaluate these crop management impacts. We suggest that the differences in carbon balance between Auradé and Lamasquère are mostly due to differences in the type of farm: cereal production at Auradé and cattle breeding at Lamasquère.

Despite the fact that the carbon storage potential of croplands seems to be poor, long term monitoring experiments are very important to evaluate the carbon balance of different rotations cycles, with various climate and physical backgrounds. It will provide insights into which rotations, crop species and crop management techniques can mitigate carbon release to the atmosphere and improve carbon sequestration in the context of climate change and increasing earth population and food needs. 


\section{Acknowledgements}

This work was made possible through the support of the French Ministry In Charge of Research ("Réseau Terre et Espace"), the Ministry In Charge of Environment (GICC programme), the Centre National de la Recherche Scientifique (CNRS), the Institut National des Sciences de l'Univers (INSU), the Centre National d'Etudes Spatiales (CNES), and the Région Midi-Pyrénées Council. We are very grateful to Mr Andréoni, farmer, and to Michel Gay, Jean-Paul Kummel and Benoît Cantaloube from the Ecole Supérieure d'Agriculture de Purpan for accommodating our measurement devices in their respective fields of Lamasquère and Auradé. Special thanks to our technical staff, Hervé Gibrin, Pascal Keravec and Bernard Marciel.

\section{Reference}

Alton, P.B., North, P.R., Los, S.O., 2007. The impact of diffuse sunlight on canopy light-use efficiency, gross photosynthetic product and net ecosystem exchange in three forest biomes. Global Change Biology 13 (4), 776-787.

Ammann, C., Meixner, F.X., Busch, J., Losch, R., 1996. $\mathrm{CO}_{2}$ and $\mathrm{H}_{2} \mathrm{O}$ gas exchange of a triticale field: II. Micrometeorological flux studies and comparison with upscaling from porometry. Physics and Chemistry of The Earth 21 (3), 151-155.

Anthoni, P.M., Freibauer, A., Kolle, O., Schulze, E.-D., 2004a. Winter wheat carbon exchange in Thuringia, Germany. Agricultural and Forest Meteorology 121 (12), 55-67.

Anthoni, P.M., et al., 2004b. Forest and agricultural land-use-dependent $\mathrm{CO}_{2}$ exchange in Thuringia, Germany. Global Change Biology 10 (12), 2005-2019.

Aubinet, M., et al., 2001. Long term carbon dioxide exchange above a mixed fores in the Belgian Ardennes. Agricultural and Forest Meteorology 108 (4), 293-315.

Aubinet, M., et al., 2000. Estimates of the annual net carbon and water exchange of forests: the EUROFLUX methodology. Advances in Ecological Research 30 114-175.

Aubinet, M., et al. Carbon sequestration by a crop during a four year rotational cycle Q2 Agricultural and Forest Meteorology, submitted for publication

Baker, J.M., Griffis, T.J., 2005. Examining strategies to improve the carbon balance of corn/soybean agriculture using eddy covariance and mass balance techniques. Agricultural and Forest Meteorology 128 (3-4), 163-177.

Baldocchi, D.D. 1994. A comparative study of mass and energy exchange rates over a closed $\mathrm{C} 3$ (wheat) and an open $\mathrm{C} 4$ (corn) crop: II. $\mathrm{CO}_{2}$ exchange and water use efficiency. Agricultural and Forest Meteorology 67, 291-321.

Baldocchi, D.D., 2003. Assessing the eddy covariance technique for evaluating carbon dioxide exchange rates of ecosystems: past, present and future. Global Change Biology 9, 479-492.

Bernacchi, C.J., Hollinger, S.E., Meyers, T., 2005. The conversion of the corn/soybean ecosystem to no-till agriculture may result in a carbon sink. Global Change Biology 11 (11), 1867-1872.

Bernacchi, C.J., Hollinger, S.E., Meyers, T.P., 2006. The conversion of the corn/ soybean ecosystem to no-till agriculture may result in a carbon sink. Global Change Biology 12 (8), 1585-1586.

Demarez, V., Duthoit, S, Baret, F., Weiss, M. and Dedieu, G. Estimation of leaf area and clumping indexes of crops with hemispherical photographs. Agricultura

Q3 and Forest Meteorology, in press.

Desjardins, R.L., Sivakumar, M.V.K., de Kimpe, C., 2007. The contribution of agriculture to the state of climate: Workshop summary and recommendations Agricultural and Forest Meteorology 142 (2-4), 314-324.

Dobermann, A., Baker, J.M., Walters, D.T., 2006. Comment on "Carbon budget of mature no-till ecosystem in North Central Region of the United States". Agricultural and Forest Meteorology 136 (1-2), 83-84.

Dolman, A.J., et al., 2006. The CarboEurope Regional Experiment Strategy. Bulletin of the American Meteorological Society 87 (10), 1367-1379.

Dragoni, D., Schmid, H.P., Grimmond, C.S.B., Loescher, H.W., 2007. Uncertainty of annual ecosystem productivity estimated using eddy covariance flux measurements. Journal of Geophysical Research 112 (D17102), 1-9.

Falge, E., et al., 2001. Gap filling strategies for defensible annual sums of net ecosystem exchange. Agricultural and Forest Meteorology 107, 43-69.

Falge, E., et al., 2002. Seasonality of ecosystem respiration and gross primary production as derived from FLUXNET measurements. Agricultural and Forest Meteorology 113, 53-74

Foken, T., et al., 2004. Post-field data quality control. In: Lee, X., Massman, W., Law, B.E. (Eds.), Handbook of Micrometeorology. Kluwer Academic Publishers, pp. $181-203$.

Foken, T., Wichura, B., 1996. Tools for quality assessment of surface-based flux measurements. Agricultural and Forest Meteorology 78 (1-2), 83-105.

Gilmanov, T.G., et al., 2003. Gross primary production and light response parameters of four Southern Plains ecosystems estimated using long-term $\mathrm{CO}_{2}$-flux tower measurements. Global Biogeochemical Cycles 17 (2), 401-416.
Göckede, M., Rebmann, C., Foken, T., 2004. A combination of quality assessment tools for eddy covariance measurements with footprint modelling for the characterisation of complex sites. Agricultural and Forest Meteorology 127, 175-188.

Goulden, M.L., Munger, J.W., Fan, S.-M., Daube, B.C., Wofsy, S.C., 1996. Measurements of carbon sequestration by long-term eddy covariance: methods and a critical evaluation of accuracy. Global Change Biology 2 (3), 169-182.

Grant, R.F., et al., 2007. Net biome productivity of irrigated and rain fed maize soybean rotations: modelling vs measurements. Agronomy Journal 99 (6), 1404-1423.

Grelle, A., Lindroth, A., 1996. Eddy-correlation system for long-term monitoring of fluxes of heat, water vapour and $\mathrm{CO}_{2}$. Global Change Biology 2, 297-307.

$\mathrm{Gu}$, L., et al., 2002. Advantages of diffuse radiation for terrestrial ecosystem productivity. Journal of Geophysical Research 107 (D6), 4050 2-12-23.

$\mathrm{Gu}$, L., et al., 2005. Objective threshold determination for nightime eddyflux filtering. Agricultural and Forest Meteorology 128, 179-197.

Hollinger, S.E., Bernacchi, C.J., Meyers, T.P., 2005. Carbon budget of mature no-till ecosystem in North Central Region of the United States. Agricultural and Forest Meteorology 130 (1-2), 59-69.

Hollinger, S.E., Bernacchi, C.J., Meyers, T.P., 2006. Corrigendum to "Carbon budget of mature no-till ecosystem in North Central Region of the United States [Agric. For. Meteorol. 130 (2005) 59-69]" Agricultural and Forest Meteorology 136 (12), 88-89.

Hutchinson, J.J., Campbell, C.A., Desjardins, R.L., 2007. Some perspectives on carbon sequestration in agriculture. Agricultural and Forest Meteorology 142 (2-4), 288-302.

Jun, L., et al., 2006. Carbon dioxide exchange and the mechanism of environmental control in a farmland ecosystem in North China Plain. Science in China Series D 49 (Suppl. II), 226-240.

Kljun, N., Calanca, P., Rotach, M.P., Schmid, H.P., 2004. A simple parameterisation for flux footprint predictions. Boundary-Layer Meteorology 112, 503-523.

Law, B.E., et al., 2002. Environmental controls over carbon dioxide and water vapour exchange of terrestrial vegetation. Agricultural and Forest Meteorology $113(1-4), 97-120$.

Lloyd, J., Taylor, J.A., 1994. On the temperature dependence of soil respiration. Functional Ecology 8 (3), 315-323.

Lohila, A., Aurela, M., Tuovinen, J.P., Laurila, T., 2004. Annual $\mathrm{CO}_{2}$ exchange of a peat field growing spring barley or perennial forage grass. Journal of Geophysical Research-Atmospheres 109 (D18).

Moncrieff, J.B., Malhi, Y., Leuning, R., 1996. The propagation of errors in long-term measurements of land-atmosphere fluxes of carbon and water. Global Change Biology 2 (3), 231-240.

Moncrieff, J.B., et al., 1997. A system to measure surface fluxes of momentum, sensible heat, water vapour and carbon dioxide. Journal of Hydrology 188-189, 589-611.

Moore, C.J., 1986. Frequency response corrections for eddy correlation systems. Boundary-Layer Meteorology 37 (1-2), 17-35.

Moureaux, C., Debacq, A., Bodson, B., Heinesch, B., Aubinet, M., 2006. Annual net ecosystem carbon exchange by a sugar beet crop. Agricultural and Forest Meteorology 139 (1-2), 25-39.

Papale, D., et al., 2006. Towards a standardized processing of Net Ecosystem Exchange measured with eddy covariance technique: algorithms and uncertainty estimation. Biogeosciences 3, 571-583.

Pattey, E., Strachan, I.B., Desjardins, R.L., Massheder, J., 2002. Measuring nighttime $\mathrm{CO}_{2}$ flux over terrestrial ecosystems using eddy covariance and nocturnal boundary layer methods. Agricultural and Forest Meteorology 113, 145-158.

Raddatz, R.L., 2007. Evidence for the influence of agriculture on weather and climate through the transformation and management of vegetation: Illustrated by examples from the Canadian Prairies. Agricultural and Forest Meteorology $142(2-4), 186-202$

Rannik, U., Kolari, P., Vesala, T., Hari, P., 2006. Uncertainties in measurement and modelling of net ecosystem exchange of a forest. Agricultural and Forest Meteorology 138 (1-4), 244-257.

Reichstein, M., et al., 2005. On the separation of net ecosystem exchange into assimilation and ecosystem respiration: review and improved algorithm. Global Change Biology 11 (9), 1424-1439.

Richardson, A.D. Hollinger, D.Y, 2007. A method to-estimate the additional uncertainty in gap-filled NEE resulting from long gaps in the $\mathrm{CO}_{2}$ flux record. Agricultural and Forest Meteorology, in press 2 .

Richardson, A.D., et al., 2006. A multi-site analysis of random error in tower-based measurements of carbon and energy fluxes. Agricultural and Forest Meteorology 136 (1-2), 1-18.

Robert, M., Saugier, B., 2003. Contribution des écosystèmes continentaux à la séquestration du carbone. Contribution of terrestrial ecosystems to carbon sequestration. Comptes Rendus Geosciences 335 (6-7), 577-595.

Ruimy, A., Jarvis, P.G., Baldocchi, D.D., Saugier, B., 1995. $\mathrm{CO}_{2}$ fluxes over plant canopies and solar radiation: a review. Ecological Research 26, 1-68.

Ruppert, J., Mauder, M., Thomas, C., Lüers, J., 2006. Innovative gap-filling strategy for annual sums of $\mathrm{CO}_{2}$ net ecosystem exchange. Agricultural and Forest Meteorology $138(1-4), 5-18$.

Saito, M., Miyata, A., Nagai, H., Yamada, T., 2005. Seasonal variation of carbon dioxide exchange in rice paddy field in Japan. Agricultural and Forest Meteorology 135 (1-4), 93-109.

Salinger, M.J., 2007. Agriculture's influence on climate during the Holocene. Agricultural and Forest Meteorology 142 (2-4), 96-102. 
Smith, P., et al., 2005. Carbon sequestration potential in European croplands has been overestimated. Global Change Biology 11, 2153-2163.

Soegaard, H., et al., 2003. Carbon dioxide exchange over agricultural landscape using eddy correlation and footprint modelling. Agricultural and Forest Meteorology 114, 153-173.

Suyker, A., Verma, S., Burba, G., Arkebauer, T.J., 2005. Gross primary production and ecosystem respiration of irrigated maize and irrigated soybean during a growing season. Agricultural and Forest Meteorology 131, 180-190.

Suyker, A.E., et al., 2004. Growing season carbon dioxide exchange in irrigated and rainfed maize. Agricultural and Forest Meteorology $124(1-$ 2), 1-13.
Verma, S.B., et al., 2005. Annual carbon dioxide exchange in irrigated and rainfed maize-based agroecosystems. Agricultural and Forest Meteorology 131 (1-2), 77-96.

Webb, E.K., Pearman, G.I., Leuning, R., 1980. Correction of flux measurement for density effects due to heat and water vapour transfer. Quarterly Journal of the Royal Meteorological Society 106, 85-100.

Wohlfahrt, G., et al., 2005. Quantifying nighttime ecosystem respiration of a meadow using eddy covariance, chambers and modelling. Agricultural and Forest Meteorology 128 (3-4), 141-162.

$\mathrm{Xu}, \mathrm{L}$., Baldocchi, D.D., 2004. Seasonal variation in carbon dioxide exchange over a Mediterranean annual grassland in California. Agricultural and Forest Meteorology 123 (1-2), 79-96. 